\title{
Integrating field, textural, and geochemical monitoring to track eruption triggers and dynamics: a case study from Piton de la Fournaise
}

\author{
Lucia Gurioli $^{1}$, Andrea Di Muro ${ }^{2}$, Ivan Vlastélic ${ }^{1}$, Séverine Moune ${ }^{1}$, Simon Thivet ${ }^{1}$, Marina Valer ${ }^{1}$, \\ Nicolas Villeneuve ${ }^{2,3}$, Guillaume Boudoire ${ }^{2,3}$, Aline Peltier ${ }^{2}$, Patrick Bachèlery ${ }^{1}$, Valérie Ferrazzini ${ }^{2}$, Nicole Métrich ${ }^{2}$, \\ Mhammed Benbakkar ${ }^{1}$, Nicolas Cluzel ${ }^{1}$, Christophe Constantin ${ }^{1}$, Jean-Luc Devidal ${ }^{1}$, Claire Fonquernie ${ }^{1}$, and \\ Jean-Marc Hénot ${ }^{1}$ \\ ${ }^{1}$ Université Clermont Auvergne, CNRS, IRD, OPGC, Laboratoire Magmas et Volcans, 63000 Clermont-Ferrand, France \\ ${ }^{2}$ Institut de Physique du Globe (IPGP), Sorbonne Paris-Cite, CNRS UMR-7154, Université Paris Diderot, \\ Observatoire Volcanologique du Pitonde la Fournaise (OVPF), Bourg-Murat, France \\ ${ }^{3}$ Laboratoire Géosciences Réunion, Université de La Réunion, Institut de Physique du Globe de Paris, Sorbonne Paris-Cité, \\ UMR 7154 CNRS, 97715 Saint-Denis, France
}

Correspondence: Lucia Gurioli (lucia.gurioli@uca.fr)

Received: 29 August 2017 - Discussion started: 13 September 2017

Revised: 13 December 2017 - Accepted: 7 January 2018 - Published: 16 April 2018

\begin{abstract}
The 2014 eruption at Piton de la Fournaise (PdF), La Réunion, which occurred after 41 months of quiescence, began with surprisingly little precursory activity and was one of the smallest so far observed at PdF in terms of duration (less than 2 days) and volume (less than $0.4 \times 10^{6} \mathrm{~m}^{3}$ ). The pyroclastic material was composed of golden basaltic pumice along with fluidal, spiny iridescent and spiny opaque basaltic scoria. Density analyses performed on 200 lapilli reveal that while the spiny opaque clasts are the densest $\left(1600 \mathrm{~kg} \mathrm{~m}^{-3}\right)$ and most crystalline ( 55 vol. $\%)$, the golden pumices are the least dense $\left(400 \mathrm{~kg} \mathrm{~m}^{-3}\right)$ and crystalline $(8 \mathrm{vol} . \%)$. The connectivity data indicate that the fluidal and golden (Hawaiianlike) clasts have more isolated vesicles (up to 40 vol. \%) than the spiny (Strombolian-like) clasts $(0-5$ vol. \%). These textural variations are linked to primary pre-eruptive magma storage conditions. The golden and fluidal fragments track the hotter portion of the melt, in contrast to the spiny fragments and lava that mirror the cooler portion of the shallow reservoir. Exponential decay of the magma ascent and output rates through time revealed depressurization of the source during which a stratified storage system was progressively tapped. Increasing syn-eruptive degassing and melt-gas decoupling led to a decrease in the explosive intensity from early fountaining to Strombolian activity. The geochemical results confirm the absence of new input of hot magma into
\end{abstract}

the 2014 reservoir and confirm the emission of a single shallow, differentiated magma source, possibly related to residual magma from the November 2009 eruption. Fast volatile exsolution and crystal-melt separation (second boiling) were triggered by deep pre-eruptive magma transfer and stress field change. Our study highlights the possibility that shallow magma pockets can be quickly reactivated by deep processes without mass or energy (heat) transfer and produce hazardous eruptions with only short-term elusive precursors.

\section{Introduction}

A detailed characterization and understanding of eruptive dynamics and of processes driving and modulating volcano unrest are crucial in monitoring active volcanoes and fundamental for forecasting volcanic eruptions (Sparks, 2003). Many studies suggest that eruptive phenomena are strongly dependent on the physico-chemical properties of ascending magma in the conduit (e.g. temperature, viscosity, porosity, and permeability) (e.g. Sparks, 1978; Rust and Cashman, 2011; Gonnermann and Manga, 2013; Polacci et al., 2014). Integrating petrographic, chemical, and textural data can thus provide critical information to constrain both the 
pre-eruptive storage conditions and the processes related to magma ascent, degassing, and cooling (e.g. reference in Table 1 in Gurioli et al., 2015). This multidisciplinary approach is of even greater importance in the monitoring of volcanoes that emit relatively uniform magma compositions over time, like basaltic volcanoes (e.g. Di Muro et al., 2014; Gurioli et al., 2015; Coppola et al., 2017). As a result, monitoring of textures and petrochemical properties of lava fragments and pyroclasts is now routinely carried out on a daily basis at active volcanoes such as Kīlauea, Etna, and Stromboli (e.g. Taddeucci et al., 2002; Thornber et al., 2003; Polacci et al., 2006; Swanson et al., 2009; Colò et al., 2010; Houghton et al., 2011, 2013, 2016; Carey et al., 2012, 2013; Lautze et al., 2012; Andronico et al., 2013a, b, 2014; Corsaro and Miraglia, 2014; Di Muro et al., 2014; Gurioli et al., 2014; Eychenne et al., 2015; Leduc et al., 2015; Kahl et al., 2015). In the past, time series of petrographic and geochemical data have been measured for Piton de la Fournaise $(\mathrm{PdF})$ basalts and particularly for effusive products. The aim of these datasets was to constrain the spatial and temporal evolution of magma for one of the most active basaltic volcanoes in the world (e.g. Albarède et al., 1997; Vlastélic et al., 2005, 2007, 2009; Boivin and Bachèlery, 2009; Peltier et al., 2009; Schiano et al., 2012; Lénat et al., 2012; Di Muro et al., 2014, 2015; Vlastèlic and Pietruszka, 2016). However, this type of approach has seldom been coupled with detailed textural studies at PdF and instead has mostly focused on crystal textures and crystal size distribution (Welsch et al., 2009, 2013; Di Muro et al., 2014, 2015). Moreover, only sporadic data exist on the textures of pyroclasts ejected by the eruptions at PdF (Villemant et al., 2009; Famin et al., 2009; Welsch et al., 2009, 2013; Michon et al., 2013; Vlastélic et al., 2013; Di Muro et al., 2015; Morandi et al., 2016; Ort et al., 2016).

Within this paper, we present a multidisciplinary textural, chemical, and petrological approach to quantify and understand the short-lived 2014 PdF eruption. This approach combines detailed study of the pyroclastic deposit (grain size and componentry) with bulk texture analysis (density, vesicularity, connectivity, permeability, morphology, vesicle distribution, and crystal content) and a petrochemical study (bulk rock, glass, minerals, melt inclusions) of the same clasts. This integrated approach has now been formalized within the French National Observation Service for Volcanology (SNOV), as routine observational systems Dynamics of Volcanoes (DynVolc, http:// wwwobs.univ-bpclermont.fr/SO/televolc/dynvolc/) and Observation des gaz volcaniques, (GazVolc, http://wwwobs. univ-bpclermont.fr/SO/televolc/gazvolc) to provide data for the ongoing activity at PdF (Harris et al., 2017).

In spite of being the first of a series of eruptions, the June 2014 event was preceded by only weak inflation and by a rapid increase in the number of shallow $(<2 \mathrm{~km}$ below volcano summit) volcano tectonic earthquakes that happened only 11 days before the eruption (Peltier et al., 2016). The eruptive event was dominantly effusive, lasted only $20 \mathrm{~h}$, and emitted a very small volume of magma (ca. $0.4 \times 10^{6} \mathrm{~m}^{3}$; Peltier et al., 2016), which makes this event one of the smallest, in terms of duration and volume, observed at PdF up to now. In addition, the eruption started during the night and very little direct observation exists for the first few hours of the activity when the lava effusion was associated with very weak fountaining activity and Strombolian explosions.

This eruption occurred just outside the southern border of the summit Dolomieu caldera, at the top of the central cone of PdF (Fig. 1). This is a high-risk sector because of the high number of tourists. Identification of precursors of this kind of activity represents an important challenge for monitoring systems (Bachélery et al., 2016).

Therefore this eruption represents an ideal context for applying our multidisciplinary approach, with the aim of addressing the following key questions:

i. Why was such a small volume of magma erupted instead of remaining endogenic?

ii. What caused the rapid trigger and the sudden end to this small-volume eruption?

iii. Which was the source of the eruption (shallow versus deep and single versus multiple small magma batches)?

iv. What was the ascent and degassing history of the magma?

v. What was the time and space evolution of the eruptive event?

Furthermore, this eruption provides an exceptional opportunity to study processes leading to the transition from mild Hawaiian $(<20 \mathrm{~m}$ high fountains, following the nomenclature proposed by Stovall et al., 2011) to Strombolian activity $(<10 \mathrm{~m}$ high explosions), whose products are little modified by post-fragmentation processes because of the very low intensity of the activity.

\section{The 2014 activity}

\subsection{Precursory activity}

The 20 June 2014 summit eruption represents the first eruption at PdF after 41 months of quiescence. The last eruption had been on 9 December 2010, with a shallow (above sea level) intrusion on 2 February 2011 (Roult et al., 2012). From 2011, the deformation at PdF was constant with two distinct types of behaviour: (i) a summit contraction of a few centimetres every year (Fig. 1d) and (ii) a preferential displacement of the east flank at a rate of $1-3 \mathrm{~cm}$ per year (Brenguier et al., 2012; Staudacher and Peltier, 2015). The background microseismicity was very low (less than five shallow events per day below volcano summit) and low-temperature summit intracaldera fumaroles emitted very little sulfur $\left(\mathrm{H}_{2} \mathrm{~S}\right.$ 


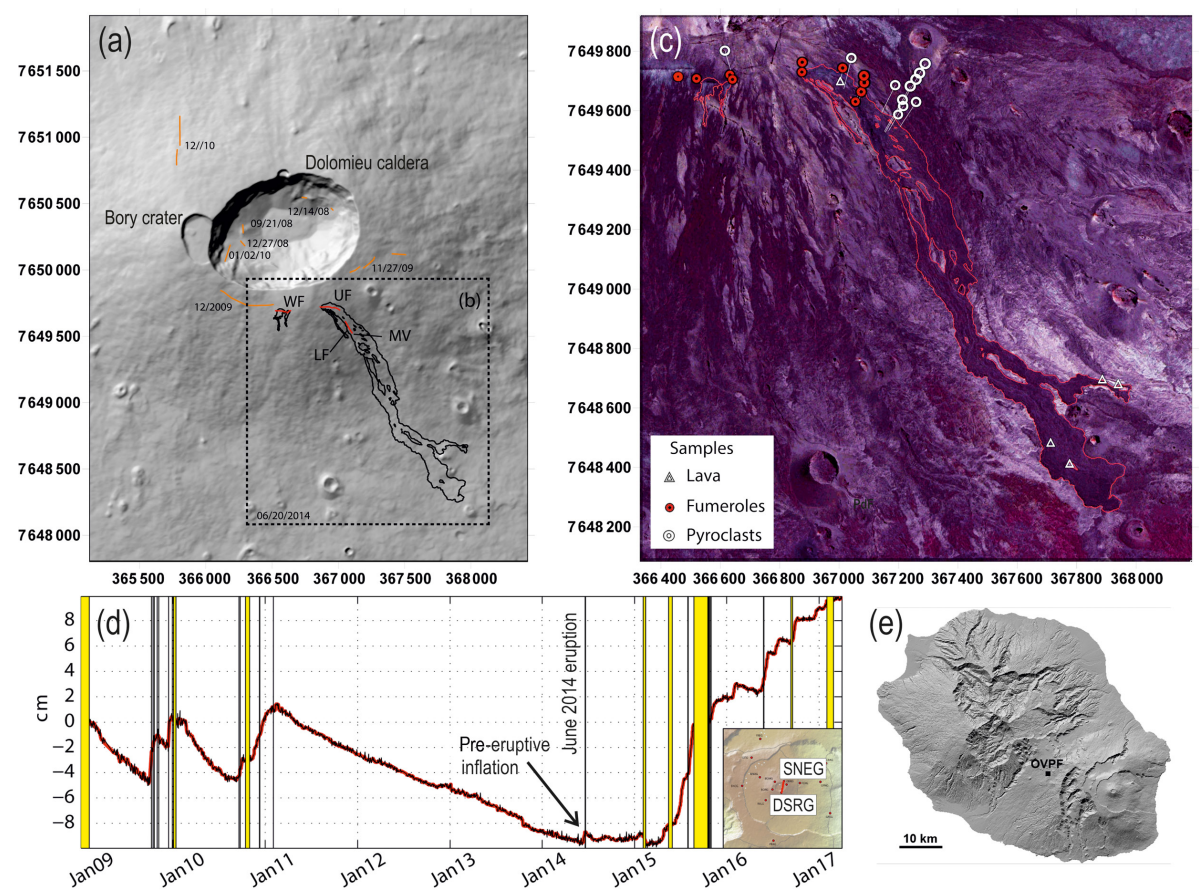

Figure 1. (a) Digital elevation model of the summit crater area at Piton de la Fournaise, La Réunion, France. Orange shows fractures generated by pre-2014 eruptions (reported are the dates of their activities); (b) red shows fractures active during the 2014 eruption: WF (western fracture), UF (upper fracture), LF (lower fracture), MV (main vent). Black shows the outline of the 2014 lava field. (c) Locations of sample collection points. The coordinates are in UTM, zone 40 south. (d) Distance change (baseline) in centimetres between two GNSS summit stations: DSRG and SNEG (see location in the inset). Increase and decrease in the signal mean a summit inflation and deflation, respectively. The yellow areas represent eruptive and intrusive periods. In (d), the rapid and strong variations linked to dike injections preceding intrusions and eruptions by a few tens of minutes have been removed. (e) Digital elevation model of La Réunion island.

or $\left.\mathrm{SO}_{2}\right)$ and carbon $\left(\mathrm{CO}_{2}\right)$ (Di Muro et al., 2016). After 41 months of rest, a new intense cycle of activity (June 2014, February 2015, May 2015, July 2015, August-October 2015, May 2016; September 2016; January 2017, and July 2017) began with surprisingly little and ambiguous precursory activity.

The 2014 summit eruption started during the night of 20 21 June, at 21:35 GMT (00:35 local time) and ended on 21 June at 17:09 GMT (21:09 local time), after less than $20 \mathrm{~h}$ of dominantly effusive activity. The volcano reawakening was preceded, in March and April 2014, by deep (15-20 km below sea level) eccentric seismicity and an increase in soil $\mathrm{CO}_{2}$ flux below the western volcano flank, $15 \mathrm{~km} \mathrm{NW}$ of the volcano summit (Liuzzo et al., 2015; Boudoire et al., 2017). Background microseismicity and inflation of the central cone increased progressively starting on 9 June 2014 . Weak inflation recorded on both distal and summit baselines (Fig. 1d) suggests that deep (below sea level) magma uprise was pressurizing the shallow (above sea level) magma storage system (Peltier et al., 2016). On 13, 17, and 20 June, three shallow (hypocentres located above sea level) intense seismic crises occurred below the summit Dolomieu caldera (Fig. 1), with hundreds of events located in a narrow depth range between 1100 and $2100 \mathrm{~m}$ below the volcano summit. These seismic crises consisted of swarms of low-magnitude (M:1-2) volcano tectonic events that increased in number from the first to the third crisis. On 20 June, seismicity increased progressively and a final seismic crisis started at 20:20 GMT, only $75 \mathrm{~min}$ before the eruption. This last seismic crisis was coupled with acceleration in the deformation of the summit area, which began only $60 \mathrm{~min}$ before the eruption. Interestingly, only slight inflation of the central cone $(<2 \mathrm{~cm}$ of dilatation) was detected 11 days before the 2014 eruption with a maximum of 1 and $1.6 \mathrm{~cm}$ enlargement at the summit and the base of the cone, respectively (Peltier et al., 2016, and Fig. 1d). A moderate increase in $\mathrm{CO}_{2}$ and $\mathrm{H}_{2} \mathrm{~S}$ emissions from summit intracaldera fumaroles was detected starting on 2 June, but only very minor $\mathrm{SO}_{2}$ emissions occurred before the eruption (mostly on 7 and 15 June, unpublished data). Therefore, the acceleration in both geophysical and geochemical parameters was mostly related to the late phase of dike propagation towards the surface just before the eruption. Following the end of the 20-21 June eruption, a long-term continuous inflation of the edifice began, at a moderate rate, and mostly at the base of the volcano. More than 1 year after this first eruption, the long-term deformation trends showed that the 2014 eruption marked a kink between the deflation trend, which followed the caldera-forming 2007 eruption (Staudacher et al., 2009), 
and the currently ongoing continuous inflation trend (Fig. 1d and Peltier et al., 2016; Coppola et al., 2017).

\subsection{Chronology of the events}

We reconstructed the chronology of the events by combining a distribution map of the fissures, pyroclastic deposits, and lava flows (Fig. 1) with a review of available images and videos extracted from the observatory database, the local newspapers, and websites (Fig. 2). The 2014 eruption occurred at the summit and on the SE slopes of the Dolomieu caldera (Fig. 1a, b, and c) and evolved quickly and continuously over $20 \mathrm{~h}$. The full set of fractures opened during a short period of time (minutes) and emitted short $(<1.7 \mathrm{~km}$ long) lava flows (Figs. 1 and $2 \mathrm{c}$ and d). Feeding vents were scattered along a $0.6 \mathrm{~km}$ long fissure set (Fig. 1a) and produced very weak (low) Hawaiian to Strombolian activity (Fig. 2).

Fissures opened from west to east, initially subparallel to the southern border of Dolomieu caldera and then propagated at lower altitude (Fig. 1). The summit part of the fractures (ca. $2500 \mathrm{~m}$ a.s.1., western fracture, WF in Fig. 1) emitted only small volumes of lava and pyroclasts. This part of the fracture set was active only during the first few hours of the eruption, at night. The eastern part of the fractures (upper fracture, UF in Fig. 1) descended to lower altitude (between 2400 and $2300 \mathrm{~m}$ a.s.l., middle fracture, Fig. 1) along the SE flank of the summit cone and emitted most of the erupted volume. As often observed in PdF eruptions, the activity progressively focused on a narrow portion of the fractures at low altitude and finally on a single vent located at the lower tip of the fracture system (main vent, at $2336 \mathrm{~m}$ a.s.1., MV in Figs. 1, 2). The first in situ observations in the morning of 21 June (ca. 04:00 GMT) showed that weak Strombolian activity (Fig. 2a and b) was focused on a narrow segment of the lower fractures and that aa lavas had already attained the elevation of $1983 \mathrm{~m}$ a.s.1. $(0.2 \mathrm{~km}$ before maximum runout, Fig. 2c). A small, weak gas plume was also blowing northwards. A single sample of partially molten lava was collected from the still active lava front and partially water quenched (REU140621-1; Table S1 in the Supplement, Fig. 2d). During most of 21 June, the activity consisted of lava effusion in three parallel lava streams (Fig. 2c) merging in a single lava flow (Fig. 2e) and weak Strombolian explosions at several closely spaced spots along the lower part of the feeding fracture. At 13:00 (GMT), only weak explosions were observed within a single small spatter cone (Fig. 2f and g). Most of the lava field was formed of open channel aa lavas. The total volume of lava was estimated by the MIROVA service (https: //www.sites.google.com/site/mirovaweb/home), with the use of MODIS images and the analyses of the flux from the spectral properties, to be within $0.34 \pm 0.12 \times 10^{6} \mathrm{~m}^{3}$ (Coppola et al., 2017). Satellite-derived volume estimates are consistent with independent photogrammetric estimates $(0.4 \pm 0.2 \times$ $10^{6} \mathrm{~m}^{3}$; Peltier et al., 2016) and rank the 2014 eruption at

\section{June 2014 eruption at PdF}
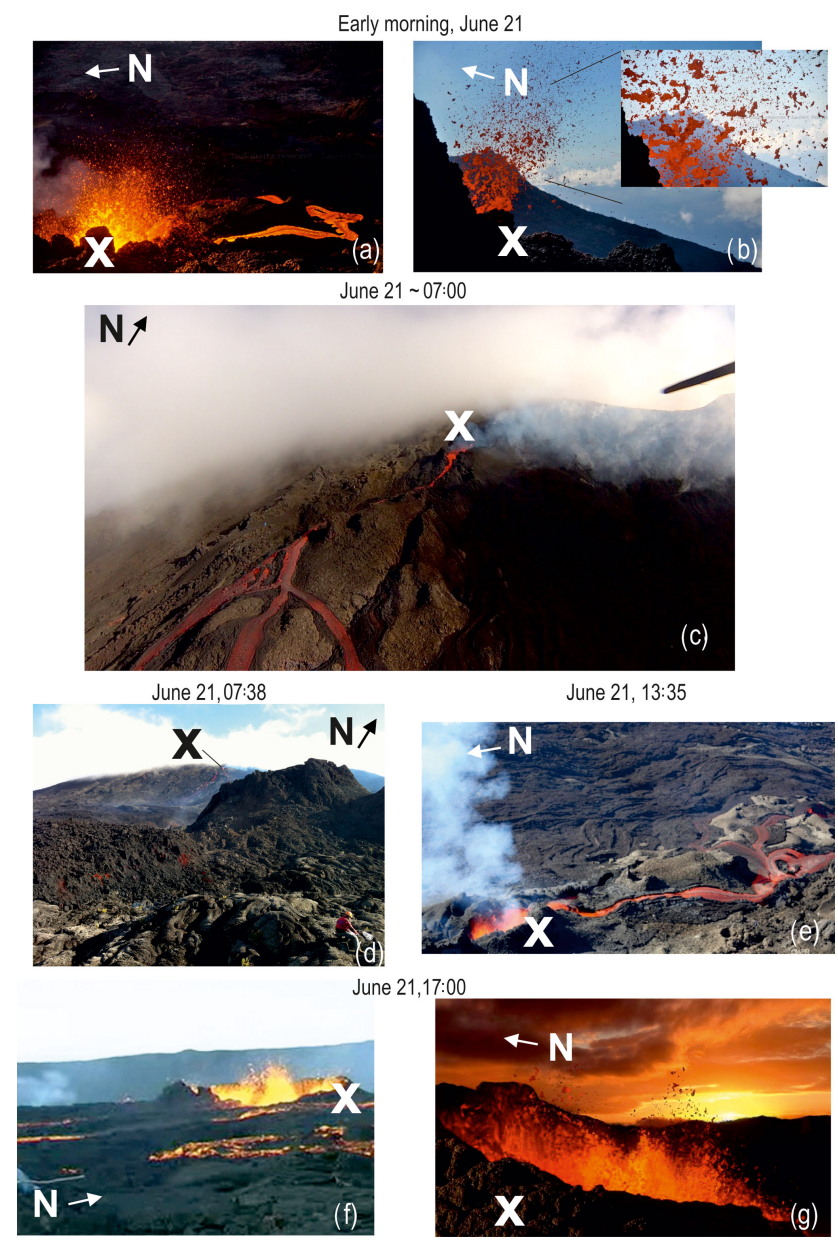

Figure 2. Photo collection from the 2014 eruption at the MV, highlighted with a white cross (see location in Fig. 1). From (a) to (g): evolution of the Strombolian activity from early morning to evening 21 June showing a decline in the activity with time. Unfortunately, the relatively more energetic Hawaiian fountaining events that happened during the night were not documented. (a) Strombolian activity at the MV and associated lava flow; (b) enlarged view of the Strombolian activity at the MV. The images in (a), (b), and the inset in (b) are from Laurent Perrier; (c) aerial view of the SE flank of PdF, taken by the OVPF team from the helicopter of the gendarmerie of La Réunion; (d) eastern front of the lava where the OVPF team collected a quenched lava sample; (e) low Strombolian activity at the MV and the associated lava flow; photo from http://www.ipreunion.com/volcan/reportage/2014/06/21/eruptiondu-piton-de-la-fournaise-actualise-a-17h-la-lave-coule-sur-

1-5- kilometre,26023.html. Panels (f) and (g) show the decline of the Strombolian activity at the MV. The photo in (e) is from http://www.zinfos974.com/ L-eruption-du-Piton-de-la-Fournaise-Le-point-de17h_a72981. html and the photo in (f) is from (f) http://nancyroc.com/ eruption-a-la-reunion. 

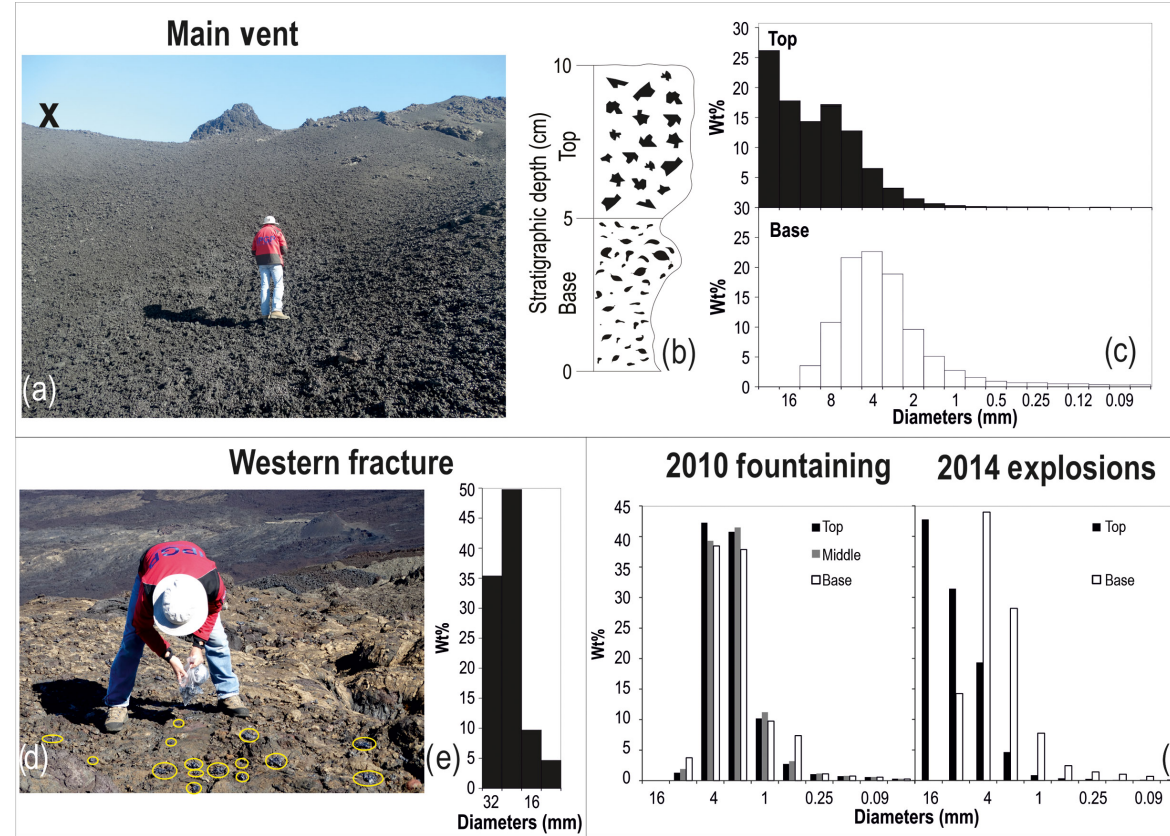

2010 fountaining 2014 explosions

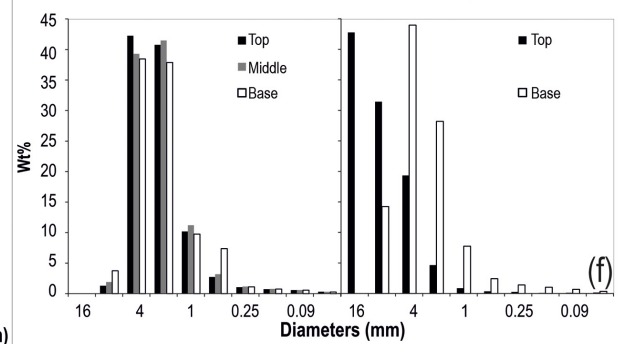

Figure 3. (a) Continuous blanket of scoria fallout deposit emitted from the MV (Fig. 1 for location) during the June 2014 eruption at PdF. The black cross locates the position of the MV (see Fig. 1 for the location). (b) Schematic stratigraphic log of the scoria fallout deposit emplaced during the June 2014 eruption at the MV. (c) Grain size histograms of the base and the top of the deposit of the MV; the particle diameters are at half phi. (d) Scattered scoria (outlined in yellow) from the WF (see Fig. 1 for the location). (e) Grain size histogram of the scoria deposit at the WF; the particle diameters are at half phi. (f) Comparison between the grain size histograms for the 2010 Hawaiian fountaining and the $2014 \mathrm{MV}$ activity; both the particle axes are reported in full phi for comparison.

the lower end of the volume range typically emitted by PdF (Roult et al., 2012).

\section{Methodology}

\subsection{Sampling strategy}

Apart from the sample from the front of the still active lava flow (Fig. 2d), all other samples were collected in two phases: 3 days (pyroclasts on 24 June, Fig. 3a and Table S1) and 11 days after the eruption (lavas on 2 July, Table S1), and 3 months later (pyroclasts from the MV, Fig. 1, on 18 November and Table S1). The 24 June samples were collected from the main fractures (WF and UF, Fig. 1a), the MV, and the active lava flow (Fig. 1 and Table S1). We collected 25 scoriaceous bombs and lapilli (REU140624-9a-1 to REU1406249a and REU140624-9b-6 to REU140624-9b-25, in Table S3) from the discontinuous deposit (Fig. 3d) emplaced at the WF site (Fig. 1a), active only at the beginning of the eruptive event. Because of the short duration of the activity at the WF, the scoria fragments on the ground were scarce (Fig. 3d). The strategy was to collect a sample that was formed by the largest available number of clasts that was representative of this discrete deposit (REU140624-9 in Table S1). From the UF (Fig. 1a) only one big scoria was collected (REU14062413, Table S1) that broke in five parts, allowing us to mea- sure its vesiculated core and the dense quenched external part (REU140624-13-a to REU140624-13-e, in Table S3). In contrast, the sustained and slightly more energetic activity at the lower tip of the fractures, at the MV site, built a small spatter cone (Fig. 2) and accumulated a continuous, smallvolume deposit (Fig. 3a) of inversely graded scoria fallout (Fig. $3 \mathrm{~b}$ and c). This deposit is $10 \mathrm{~cm}$ thick at $2 \mathrm{~m}$ from the vent and covers an area of about $\sim 1000 \mathrm{~m}^{2}$. For this fall deposit we collected two bulk samples, one from the base (within the lower $5 \mathrm{~cm}$, REU141118-6 in Table S1) and the other from the top (within the upper $5 \mathrm{~cm}$, REU140624-3, in Table S1), for the grain size (Fig. 3c) and componentry analyses. The sample at the base was collected in November because on 24 June the loose proximal lapilli blanket was still very hot $\left(405^{\circ} \mathrm{C}\right.$; thermocouple measurement $)$ and fumaroles with outlet temperatures in the range of $305-60^{\circ} \mathrm{C}$ were sampled all along the fractures several weeks after the eruption (Fig. 1b and Table S1). These latter geochemical data are not presented in this paper. We selected 103 fragments from the coarsely grained bulk deposit within the upper $5 \mathrm{~cm}$ of the scoria fallout deposit (Fig. 3b) at MV (REU140624-3-1 to REU140624-3-103, in Table S3) for density, connectivity, permeability, petrological, and geochemical analysis. In addition, in November 2014, more than 200 clasts (comprising the REU141118-1 to REU141118-5 samples, Table S1) of similar size were collected, both close to the MV and in 


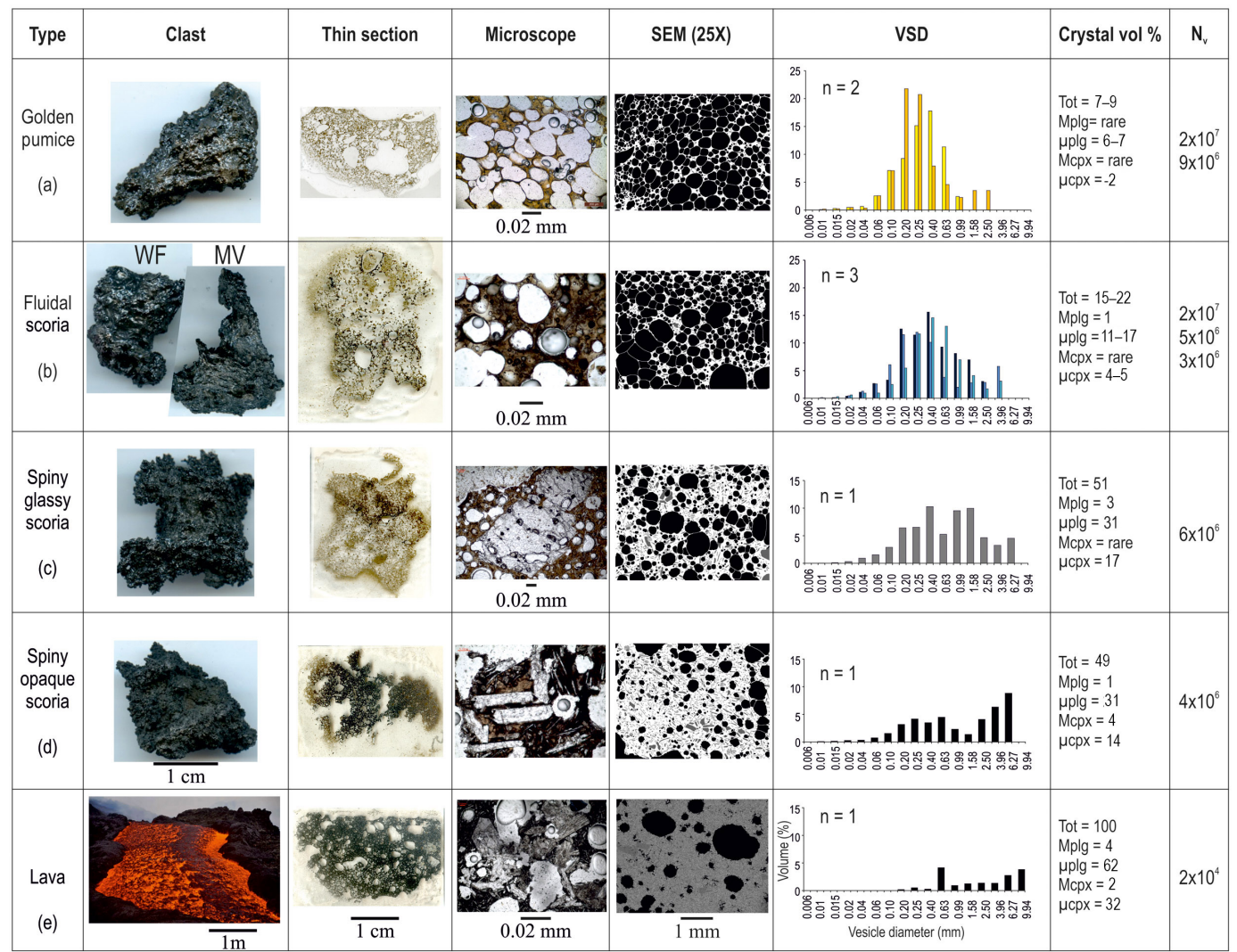

Figure 4. Textural features of June 2014 pyroclasts and lava. Clast shows a photo of the different types of juvenile pyroclasts and lava channel. The photo of the lava channel is from Laurent Perrier. WF: western fracture (smooth fluidal scoria); MV: main vent (fluidal scoria, less smooth than the ones at the WF). Thin section is the thin section imaged with a desktop scanner. Microscope is the picture taken with an optical microscope using natural light. SEM (25X) is the image captured using scanning electron microscopy (SEM) in BSE mode at $25 \mathrm{x}$ magnification: black is vesicles, white is glass, grey is crystals. VSD is the vesicle size distribution histograms, where the diameter, in millimetres, is plotted versus the volume percentage. $n$ : number of measured clasts; crystal vol. \%. Tot: total percentage of crystals corrected for the vesicularity; Mplg: percentage of mesocrysts of plagioclase; $\mu$ plg: percentage of microcrysts of plagioclase; Mcpx: percentage of mesocrysts of pyroxene; $\mu \mathrm{cpx}$ : percentage of microcrysts of pyroxene; $N_{\mathrm{v}}$ : number density corrected for the vesicularity.

the distal area (30 $\mathrm{m}$ away from the MV site) to complete the particle bulk texture analyses and the chemical analyses.

\subsection{Grain size and componentry}

We performed grain size analyses on the two bulk samples collected from the MV, following the procedure of Jordan et al. (2016) (Table S2). The samples were dried in the oven at $90^{\circ} \mathrm{C}$ and sieved at $1 / 2$ phi intervals in the range of $-5 \phi$ to $4 \phi$ (Fig. 3c); the data are also shown in full phi for comparison with the deposits of the $2010 \mathrm{PdF}$ fountaining episode (Hibert et al., 2015; Fig. 3f). Sieving was carried out by hand and for not longer than 3 min to avoid breaking and abrasion of the very vesicular and fragile clasts. For the scattered scoria sampled from the WF (Figs. 1, 3d and e), we followed the grain size strategy proposed in Gurioli et al. (2013). Within this procedure we sampled each fragment and we recorded the weight and the three main axes ( $a$ being the largest, $b$, and c). To allow comparison with the sieving grain size analyses
(Inman, 1952), we used the intermediate $\mathrm{b}$ axis dimension to obtain $\phi=-\log _{2} \mathrm{~b}$.

Following the nomenclature of White and Houghton (2006) the componentry analysis is the subdivision of the sample into three broad components: (i) juvenile, (ii) non-juvenile particles, and (iii) composite clasts. The juvenile components are vesicular or dense fragments, as well as crystals, that represent the primary magma involved in the eruption; non-juvenile material includes accessory and accidental fragments, as well as crystals that predate the eruption from which they are deposited. Finally, the composite clasts are mechanical mixtures of juvenile and non-juvenile (and/or recycled juvenile) clasts. In these mild basaltic explosions, the non-juvenile component is very scarce, so we focused on the juvenile component that is characterized by three groups of scoria: (i) spiny opaque, (ii) spiny glassy, and (iii) fluidal, along with golden pumice (Fig. 4). The componentry quantification was performed for each grain size fraction between $-5 \phi$ and $0.5 \phi$ (Fig. 5a 

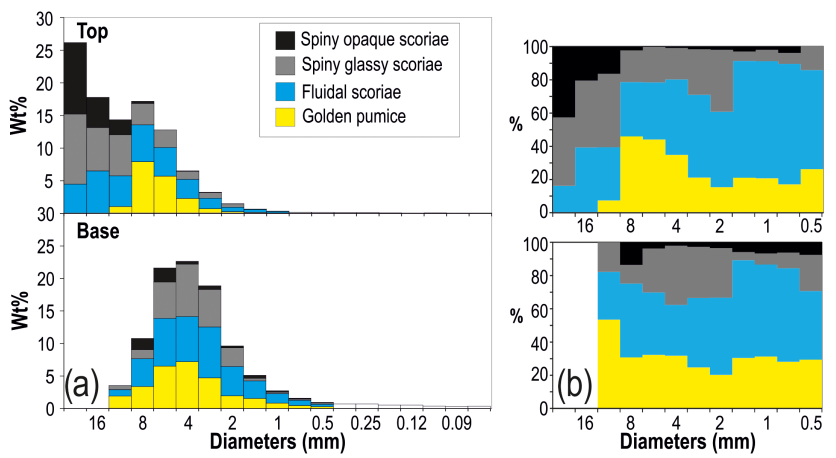

Figure 5. Proportion of each type of clast measured from the base to the top of the $10 \mathrm{~cm}$ thick deposit emplaced during the eruption, at the MV site. The deposit is dominated by Hawaiian-like lapilli fragments at the base (golden pumice and fluidal scoria) and Strombolian-like bombs and lapilli at the top (spiny scoria): (a) componentry within the different grain size classes; (b) normalized componentry composition from the base to the top of the deposit.

and b), and a binocular microscope was used for the identification of grains smaller than -1 (Table S2).

In the following, we will use the crystal nomenclature of Welsch et al. (2009), with the strictly descriptive terms of macrocrysts $(>3 \mathrm{~mm}$ in diameter) mesocrysts (from 0.3 to $3 \mathrm{~mm}$ in diameter), and microcrysts ( $<0.3 \mathrm{~mm}$ in diameter). Regarding the June 2014 products, these ranges of size may however change in comparison to the December 2005 products studied by Welsch et al. (2009).

\subsection{Particle bulk texture (density, porosity, connectivity, permeability) and micro-texture}

For each sample site (WF, UF, and MV; Fig. 1a), we selected all the available particles within the $8-32 \mathrm{~mm}$ fraction for density-porosity, connectivity, and permeability measurements (Table S3). This is the smallest granulometric fraction assumed to be still representative of the larger size class in terms of density (Houghton and Wilson, 1989; Gurioli et al., 2015) and has been used in previous textural studies (e.g. Shea et al., 2010). In addition, this size range is ideal for vesicle connectivity measurements (e.g. Formenti and Druitt, 2003; Giachetti et al., 2010; Shea et al., 2012; Colombier et al., 2017a, b). Density of juvenile particles was measured using the water-immersion technique of Houghton and Wilson (1989), which is based on Archimedes' principle. A mean value for the vesicle-free rock density was determined by powdering clasts of varying bulk densities, measuring the volumes of known masses using an AccuPyc II 1340 helium pycnometer, and then averaging. The same pycnometer was also used to measure vesicle interconnectivity for each clast using the method of Formenti and Druitt (2003) and Colombier et al. (2017a). Permeability measurements were performed on five clasts: two golden pumices, one flu-
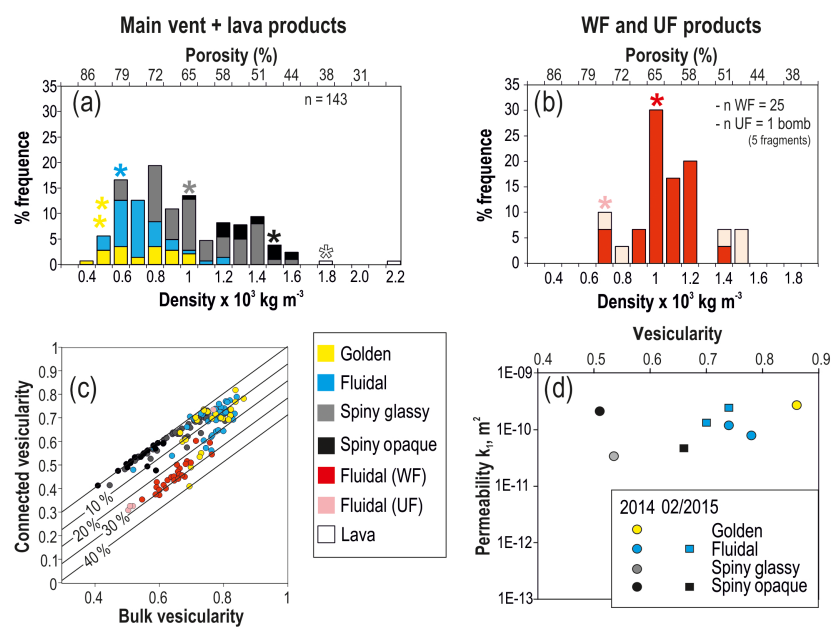

Figure 6. Density, connectivity, and permeability data of June 2014 pyroclast and lava fragments: (a) density distribution histogram for all the pyroclast fragments measured at the MV + two lava fragments collected from the eastern front of the lava flow (see Fig. 1 for location). $n$ is the number of measured clasts; (b) density distribution histogram for the pyroclasts sampled at the WF and the bomb sampled at the UF. The bomb broke in five fragments (two fragments from the core, the least dense, and three fragments from the quenched edges, the densest). In both the density histograms the stars represent the density intervals from which we picked the clasts for the textural measurements; (c) graph of the connected vesicularity versus total vesicularity. The diagonal line represents equality between the connectivity and vesicularity; beneath this line the samples have isolated vesicles and the straight lines represent lines of equal fraction of isolated vesicles. Note that the bomb from the UF has the high vesicular core with less than $5 \%$ of isolated vesicles, while the three low vesicular fragments from the quenched edge have more than $25 \%$ of isolated vesicles (see pink spots); (d) Darcian viscous permeability $\left(k_{1}\right)$ versus vesicularity fraction for the four typologies of clasts collected at the MV. For comparison, two fluidal fragments and one spiny opaque fragment from the February 2015 eruption are reported.

idal, one spiny glassy, and one opaque scoria, all collected from the MV (Table S3). Following Colombier et al. (2017a), the clasts were cut into rectangular prisms to enable precise calculation of the cross-sectional area, which is required to calculate permeability. These prisms were then embedded in a viscous resin, which was left to harden for $24 \mathrm{~h}$. The sample surface had been previously coated with a more viscous resin and then wrapped with Parafilm to avoid intrusion of the less viscous resin inside the pores. The coated samples were placed with a sample holder connected to a permeameter built at Laboratoire Magmas et Volcans (LMV, France) following Takeuchi et al. (2008). The measurements were performed at atmospheric pressure (i.e. without confining pressure) and the samples were measured at a range of gas flow rates and upstream air pressures to create a curve that could be fitted using a modified version of Darcy's law (the Forchheimer equation) to solve for viscous $\left(k_{1}\right)$ and in- 
ertial permeabilities $\left(k_{2}\right)$ (Rust and Cashman, 2011; Lindoo et al., 2016; Colombier et al., 2017a, b).

Vesicle size distribution was performed following the method of Shea et al. (2010) and Leduc et al. (2015), while the total crystallinity, the percentages for both crystal phases (plagioclase and clinopyroxene), and size populations (mesoand microcrysts) were calculated using the raw data from the FOAMS program (Shea et al., 2010), the CSD corrections program of Higgins (2000), and the CSDslice database (Morgan and Jerram, 2006) to have the percentage of crystals in 3-D with the corrected assumption for shape. We performed these analyses on eight clasts picked up from each component and density distributions (stars in Fig. 6a and b). The choice of the clasts was made mostly on the typologies, rather than on each density distribution, in order to avoid the analysis of clasts with transitional characteristics. For example, two golden pumice fragments were selected from the largest clasts that were less dense and did not break, even if the values in vesicularity were similar. A larger number of fluidal fragments were chosen (even if the density distribution was unimodal) because this typology of clasts was the most abundant and was emitted all along the active fracture; thus we did our best in order to study products representative of the WF, the UF, and the MV activities. Only one spiny glassy and one spiny opaque were selected because they were emitted only at the MV. A full description of the textural measurements all performed at LMV and the raw data of these measurements are available in the DynVolc database (2017).

\subsection{Bulk geochemistry}

For the determination of the bulk chemistry (Table S4 and Fig. 7) of the different pyroclasts we selected the largest pyroclasts of golden pumice and the largest fluidal, spiny glassy and spiny opaque scoriae (Table S4). We also analysed two fragments of lava, from the beginning and the end of the eruption (Table S4). Samples were crushed into coarse chips using a steel jaw crusher and powdered with an agate mortar. Major and trace element compositions were analysed using powder (whole-rock composition). In addition, for a subset of pyroclasts, glass chips (2-5 mm in size) were hand-picked under a binocular microscope and analysed separately for trace elements. For major element analysis, powdered samples were mixed with $\mathrm{LiBO} 2$, placed in a graphite crucible, and melted in an induction oven at $1050^{\circ} \mathrm{C}$ for $4.5 \mathrm{~min}$, resulting in a homogeneous glass bead. The glass was then dissolved in a solution of deionized water and nitric acid $\left(\mathrm{HNO}_{3}\right)$ and finally diluted by a factor of 2000 . The final solutions were analysed using inductively coupled plasma atomic emission spectroscopy. Trace element concentrations were analysed following a method modified from Vlastélic et al. (2013). About $100 \mathrm{mg}$ of sample (powder and chip) was dissolved in $2 \mathrm{~mL}$ of $28 \mathrm{M}$ and $1 \mathrm{~mL}$ of $14 \mathrm{M} \mathrm{HNO}_{3}$ in a Teflon beaker for $36 \mathrm{~h}$ at $70^{\circ} \mathrm{C}$. Solutions
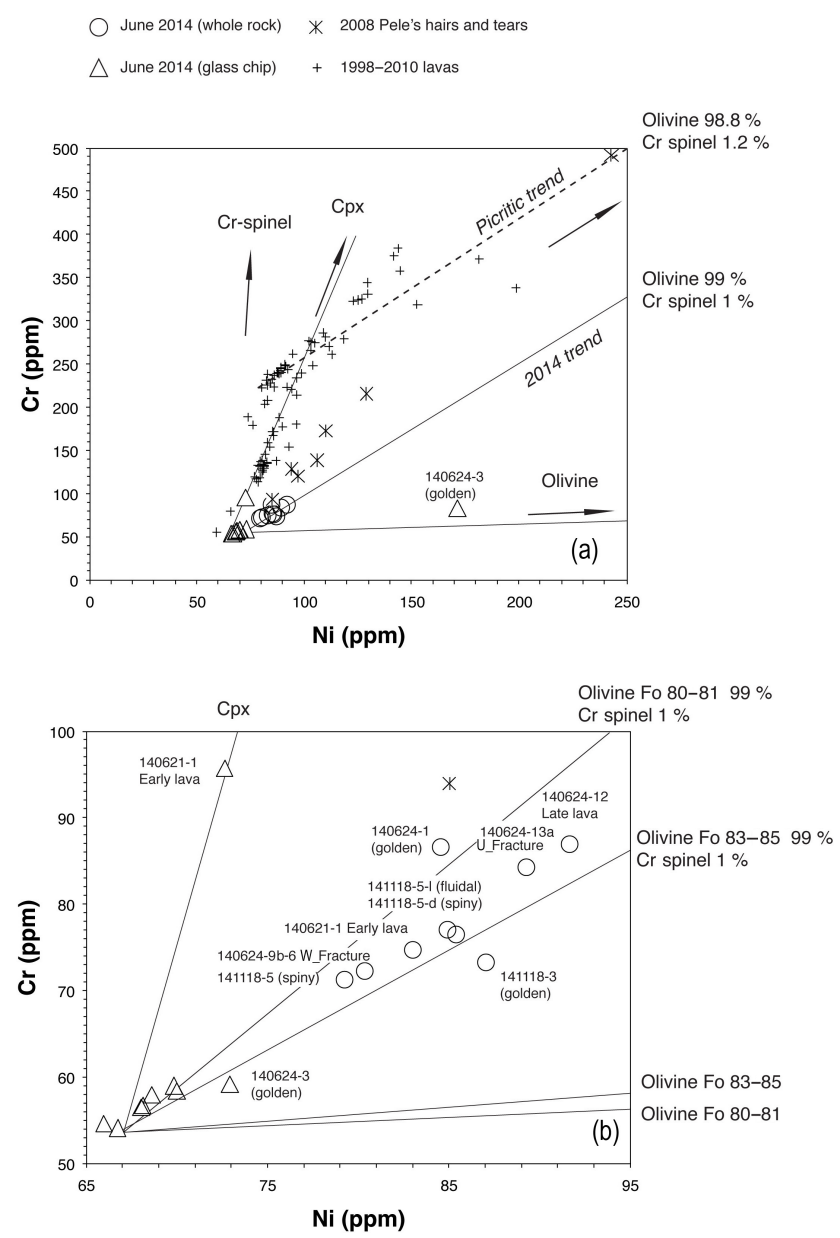

Figure 7. Ni-Cr concentration plot. (a) $\mathrm{Ni}-\mathrm{Cr}$ signature of the June 2014 lavas compared to that of recent eruptions (Di Muro et al., 2015, and unpublished data). Whole-rock (circles) and glass (triangles) compositions are shown for the June 2014 eruption. Olivine controlled lines are indicated for olivine hosting 1.2 and $0.6 \mathrm{wt} \% \mathrm{Cr}$ spinel. Compositions used for olivine $(\mathrm{Ni}=1900 \mathrm{ppm}$, $\mathrm{Cr}=300 \mathrm{ppm})$, clinopyroxene $(\mathrm{Ni}=970 \mathrm{ppm}, \mathrm{Cr}=4800 \mathrm{ppm})$, and $\mathrm{Cr}$ spinel $(\mathrm{Ni}=1500 \mathrm{ppm}, \mathrm{Cr}=25 \%)$ are inferred from Welsch et al. (2009), Salaün et al. (2010), and Di Muro et al. (2015). (b) Enlargement of the Ni-Cr relationship between glass (triangles) and whole-rock (circles) samples from the June 2014 eruption. Fracture I: western fracture; Fracture II: upper fracture. Careful sample selection has permitted us to obtain a set of fragments virtually free of olivine-cpx crystals. Any addition of mafic crystals translates into enrichment in $\mathrm{Ni}-\mathrm{Cr}$; those samples that contain a few percent of crystals (consistent with textural and petrological observation) are slightly enriched in compatible elements.

were evaporated to dryness at $70^{\circ} \mathrm{C}$. The fluoride residues were reduced by repeatedly adding and evaporating a few drops of concentrated $\mathrm{HNO}_{3}$ before being fully dissolved in ca. $20 \mathrm{~mL}$ of $7 \mathrm{M} \mathrm{HNO}_{3}$. These solutions were diluted by a factor of 15 with $0.05 \mathrm{M} \mathrm{HF}$ (to reach rock dilution factor of ca. 4000) and trace element abundances were determined with quadrupole inductively coupled plasma mass spectrom- 

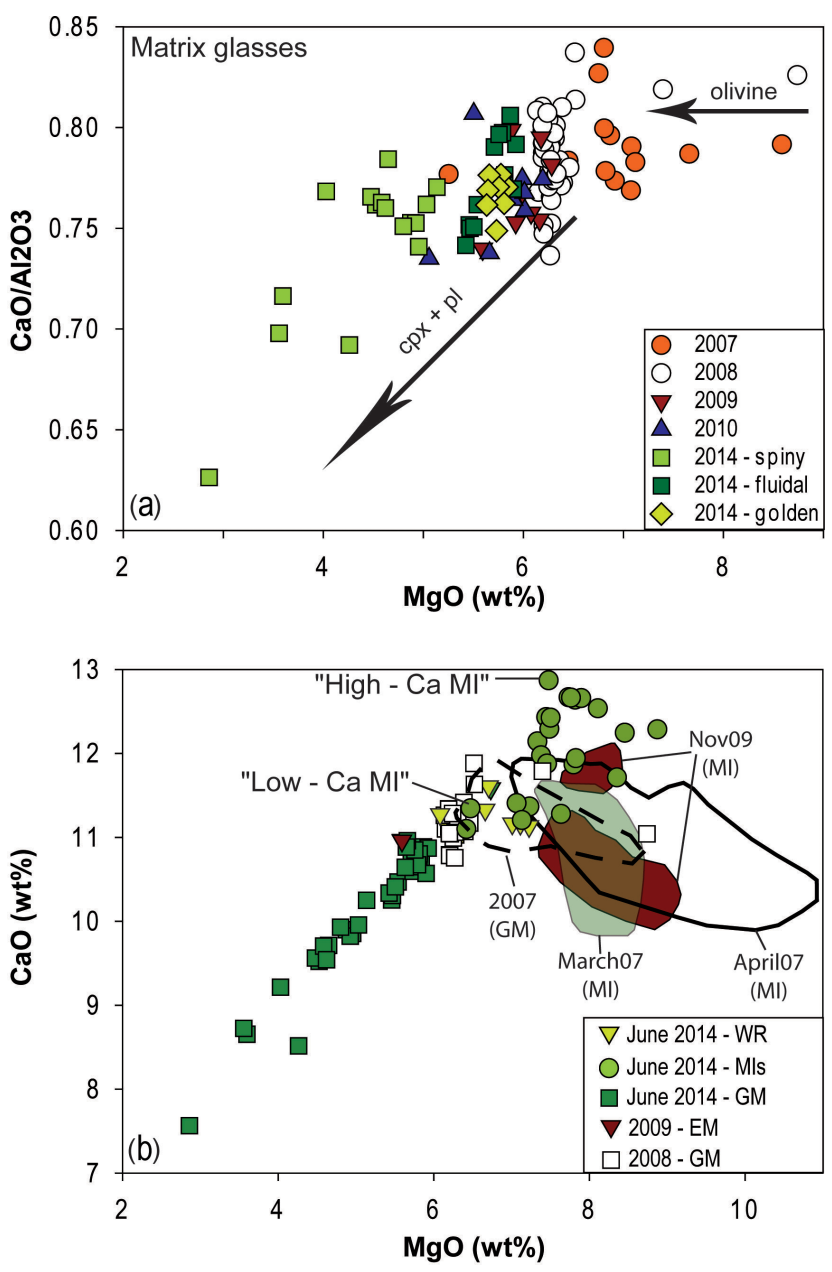

Figure 8. (a) Evolution of $\mathrm{CaO} / \mathrm{Al}_{2} \mathrm{O}_{3}$ ratio in the matrix glasses of recent eruptions at Piton de la Fournaise as a function of $\mathrm{MgO}$ content (directly proportional to melt temperature). MI is the melt inclusions (grey area for the 2014 samples). (b) $\mathrm{CaO}$ versus $\mathrm{MgO}$ content for Piton de la Fournaise products. WR: whole rock; GM: ground mass; MI: melt inclusion; EM: embayment glass.

etry (Agilent 7500). The analyses were performed in plasma robust mode $(1550 \mathrm{~W})$. The reaction cell (He mode) was used to reduce interference on masses ranging from 45 (Sc) to 75 (As). The signal was calibrated externally (every four samples) with a reference basaltic standard (USGS BHVO2) dissolved as for the samples and using the GeoReM recommended values (http://georem.mpch-mainz.gwdg.de/). For elements that are not well characterized in literature (As, $\mathrm{Bi}, \mathrm{Tl}$ ), or which show evident heterogeneity (e.g. $\mathrm{Pb}$ ) in BHVO-2 powder, the signal was calibrated using the certified concentrations of a synthetic standard, which was also repeatedly measured. The external reproducibility ( $2 \sigma$ error) of the method is $6 \%$ or less for lithophile elements and $15 \%$ or less for chalcophile elements.

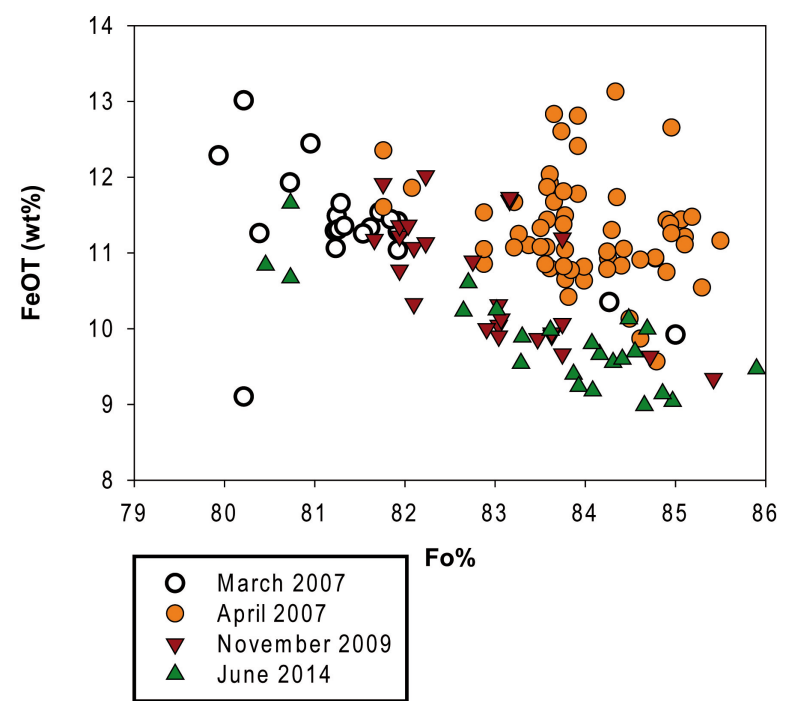

Figure 9. $\mathrm{FeO}_{T}$ in melt inclusions as a function of forsterite (Fo) content of the olivine host for recent eruptions at Piton de la Fournaise.

\subsection{Glass and crystal chemistry}

Spot analyses of matrix glass and crystal composition (Table S5) were carried out using a Cameca SX100 electron microprobe (LMV), with a $15 \mathrm{kV}$ acceleration voltage of a $4 \mathrm{nA}$ beam current with a $15 \mathrm{kV}$ acceleration voltage and a beam of $5 \mu \mathrm{m}$ diameter for glass analyses. However, for the spiny opaque scoria, characterized by abundant crystals with rapid growth textures, an $8 \mathrm{nA}$ beam current and a beam of $10 \mu \mathrm{m}$ diameter were used. For this latter sample, 10 analyses per sample were performed due to the heterogeneity within the highly crystallized glass (Fig. 8a), while for the other samples six analyses per sample were enough to characterize the clean homogeneous glass. For crystal analysis, a focused beam was used. For the characterization of the meso- and microcrysts, due to their small size, only two to three measurements were performed, one at the edge, one in the middle and one at the core of the crystals, to check for possible zonation.

\subsection{Melt inclusions}

Melt inclusions (MIs; Table S6, Figs. 8b and 9) were characterized in the olivine mesocrysts from the three groups of scoriae (fluidal, spiny glassy and spiny opaque) but not in the pumice group because crystals were too rare and small to be studied for MIs.

Olivine crystals were handpicked under a binocular microscope from the 100-250 and 250-600 $\mu \mathrm{m}$ grain size fractions of crushed tephra. Crystals with MIs were washed with acetone, embedded in epoxy and polished individually to generate adequate exposure of the MIs for in situ electron probe microanalysis. The MIs are spherical to oblate in shape and range in size from 10 to $200 \mu \mathrm{m}$. Some of the MIs contain 
shrinkage bubbles but all of those studied are totally deprived of daughter minerals. Major elements were measured on a Cameca SX100 microprobe at LMV (Table S6). For major elements, the larger MIs were analysed with a spot diameter of 10-20 $\mu \mathrm{m}$ and sample current of $8 \mathrm{nA}$, whereas the smaller MIs were analysed with a beam of $5 \mu \mathrm{m}$ and a sample current of $4 \mathrm{nA}$. The results are given in Table S6, and analytical details and uncertainties are listed in Óladóttir et al. (2011) and Moune et al. (2012).

\section{Results}

\subsection{Deposit texture (grain size, componentry, morphology) and petrological description of the samples}

The pyroclastic deposits at the WF and UF sites (Fig. 1a) are formed by scattered homogeneous smooth fluidal (Fig. 3d) bombs and lapilli scoria. The average dimension of the fragments is around $4 \mathrm{~cm}$ (maximum axis) with bombs up to $10 \mathrm{~cm}$ and scoria lapilli up to $2 \mathrm{~cm}$ in size (Fig. 3e).

At the MV, the reversely graded deposit (Fig. 3b) is made up of lapilli and bombs, with only minor coarse ash (Fig. 3c). The lower $5 \mathrm{~cm}$ at the base is very well sorted and characterized by a perfect Gaussian distribution with a mode at $4 \mathrm{~mm}$ (Fig. 3c). In contrast, the grain size distribution of the upper $5 \mathrm{~cm}$ is asymmetrical with a main mode coarser than $22 \mathrm{~cm}$ and a second mode at $8 \mathrm{~mm}$ (Fig. 3c). This upper deposit is negatively skewed due to the abundance of coarse clasts. The dataset shows a similarity between the grain size distributions of the basal tephra ejected from the $2014 \mathrm{MV}$ and the ones for the lava fountaining of the 2010 summit event (Fig. 3f and Hibert et al., 2015). Conversely, the top of the 2014 fall differs from fountain deposits, being coarser and polymodal, and it is ascribed to dominantly Strombolian activity (Fig. 3f).

In terms of componentry of the deposits, four types of clasts were distinguished (Fig. 4): (i) golden pumice, (ii) smooth or rough fluidal scoriae, (iii) spiny glassy scoria, (iv) spiny opaque scoria. The pumices are vesicular, lowdensity fragments, characterized by a golden to light brown colour, sometimes with a shiny outer surface (Fig. 4a). They are usually rounded in shape. Golden clasts studied for textures contain a few microcrysts of plagioclase (up to $0.1 \mathrm{~mm}$ in diameter), clinopyroxene up to $0.05-0.06 \mathrm{~mm}$ in diameter and small olivine up to $0.03 \mathrm{~mm}$ in diameter (Fig. 4), together with large areas of clean, light brown glass. The fluidal scoria fragments have dark, smooth or rough shiny surfaces (Fig. 4b). They can be more or less elongated in shape and have spindle as well as flattened shapes. The fluidal fragments are characterized by rare mesocrysts of plagioclase and clinopyroxene and microcrysts of plagioclase, clinopyroxene and olivine (Fig. 4b). The spiny glassy fragments are dark, spiny scoria that range in shape from subrounded to angular (Fig. 4c). These fragments contain abundant glassy areas, while the spiny opaque fragments lack a glassy, iridescent surface. Both groups of spiny clasts are characterized by the presence of dark and light brown glass. The spiny opaque fragments are the densest fragments and have the largest number of crystals. They contain, as the most abundant phase, relatively large meso- and microcrysts of plagioclase, up to $3 \mathrm{~mm}$ long, together with meso- and microcrysts of clinopyroxene and olivine (Fig. $4 \mathrm{c}$ and d). In the dark portions of their matrix, tiny fibrous microcrysts of olivine + clinopyroxene + plagioclase + Fe-Ti oxides occur. The spiny glassy fragments have the same crystal populations as the spiny opaque ones, but their plagioclases are much smaller and attain a maximum length of only $0.3 \mathrm{~mm}$. Clusters of plagioclase and clinopyroxene and rare macrocrysts of olivine are present in both the spiny opaque and spiny glassy fragments. The olivine macrocrysts exhibit the typical compositional $\left(\mathrm{Fo}_{84.2}\right)$ and petrographic features of olivine phenocrysts described in previous studies (Clocchiatti et al., 1979; Albaréde and Tamagnan, 1988; Bureau et al., 1998a, b; Famin et al., 2009; Welsch et al., 2013). They are automorphic, fractured with oxides (mostly chromite) and MIs (Fig. 4c). Fluidal and pumice fragments studied for textures contain rare macrocrysts and mesocrysts of olivine, and the crystals are essentially microcrysts. The pumice and some fluidal fragments have lower contents of microcrysts than some fluidal and spiny fragments, with the latter having the highest microcryst content (Table S4). For comparison, two fragments of lava have been analysed as well (Table S3). The lava fragments are poorly vesiculated and completely crystalline (Fig. 4e). The lava contains the same paragenesis of crystals described in the spiny opaque fragments, with the main difference being that its matrix is completely crystallized and constituted mostly by well-formed plagioclase up to $800 \mu \mathrm{m}$ and clinopyroxene up to $500 \mu \mathrm{m}$. Scarce smaller olivines are also present. Ubiquitous tiny rounded Fe-Ti oxides provide evidence of post-emplacement crystallization.

The componentry results are reported in Fig. 5 only for the MV deposits because the deposits from the WF and UF are characterized exclusively by fluidal clasts (Fig. 3). At the base of the MV deposit, the coarse fraction of the deposit is rich in golden and fluidal components that represent more than 60-70 vol. \% (Fig. 5a and b). The proportion of the two groups is similar. In contrast, in the upper coarsely grained fall deposit, the clasts bigger than $8 \mathrm{~mm}$ are dominated by the spiny scoria fragments, while the fraction of clasts smaller than $8 \mathrm{~mm}$ show a dramatic increase in the golden and fluidal fragments, with the fluidal ones always more abundant than the golden ones (Fig. 5a and b). Abundant low-density golden, coarse lapilli pumice and bombs have been found scattered laterally up to $30 \mathrm{~m}$ from the main axis and were not found in the proximal deposit. On the basis of the high amount of pumice in the lower part of the deposit, we correlate the large, low-density clasts with the base of the proxi- 
mal deposit, and consequently we interpret them as material emitted at the beginning of the June 2014 eruptive event.

\subsection{Particle density, porosity, connectivity, permeability, and micro-texture}

Density analyses performed on 200 coarse lapilli reveal a large variation in density values from 390 to $1700 \mathrm{~kg} \mathrm{~m}^{-3}$ with a median value at $870 \mathrm{~kg} \mathrm{~m}^{-3}$ (Table S3). The fragments collected from the MV have a bimodal density distribution, with a main population of low-density fragments with a mode at $800 \mathrm{~kg} \mathrm{~m}^{-3}$ and a second and denser population centred at $1400 \mathrm{~kg} \mathrm{~m}^{-3}$ (Fig. 6a). The golden and fluidal fragments form the lower-density population and the spiny fragments are dominant in the denser population (Fig. 6a). For these samples there is a marked correlation between porosity and morphology, so that the spiny opaque clasts are the densest (up to $1600 \mathrm{~kg} \mathrm{~m}^{-3}$, with a vesicularity of $45 \mathrm{vol} . \%$ ) and the golden pumice are the least dense (minimum density of $390 \mathrm{~kg} \mathrm{~m}^{-3}$ with a vesicularity of up to $86 \mathrm{vol} . \%$; with a dense-rock equivalent density of $2880 \mathrm{~kg} \mathrm{~m}^{-3}$ ). The fluidal fragments collected at the WF (Fig. 1b) have a density range from 700 to $1400 \mathrm{~kg} \mathrm{~m}^{-3}$ and a mode at $1000 \mathrm{~kg} \mathrm{~m}^{-3}$ (Fig. 6b). The five fragments from the only bomb collected at the UF are characterized by two distinct density values: the low-density one $\left(700-800 \mathrm{~kg} \mathrm{~m}^{-3}\right)$ refers to the core of the sample, while the high-density one (1400-1500 $\mathrm{kg} \mathrm{m}^{-3}$ ) represents the quenched external rim of the bomb. Finally, the two fragments of lava show the highest-density values at 1800 and $2150 \mathrm{~kg} \mathrm{~m}^{-3}$. This last value is one of the highest found in the lava collected from 2014 up to 2017 (see Fig. 13 in Harris et al., 2017, and DynVolc, 2017).

In all these samples, the increase in vesicularity correlates with an increase in the number of small $(0.1 \mathrm{~mm})$, medium $(0.5-1 \mathrm{~mm}$ ) and large (up to $4 \mathrm{~mm}$ ) vesicles. In the fluidal clasts, these vesicles have a regular rounded or elliptical shape and are scattered throughout the sample. The low-density pumices are often characterized by the presence of a single, large central vesicle $(10-15 \mathrm{~mm})$ with the little vesicles and a few medium vesicles distributed all around it (Fig. 4). The spiny glass texture is characterized by a lower number of small vesicles than in the pumice and by the presence of mostly medium-sized vesicles, while the spiny opaque has more irregular shaped and very large (up to $10 \mathrm{~mm}$ ) vesicles with a small- and a medium-sized vesicle population. In the spiny glass samples, the glass is more or less brown, with the dark brown portions being the ones with the lowest vesicle content and the highest microcryst content. The opaque samples have a central, very dark glass portion, with low vesicle content, and a more vesicular glassy portion at the outer edges (Fig. 4). The two fragments of lava are poorly vesiculated (Fig. 6a) and characterized by large, irregular vesicles (up to $5 \mathrm{~mm}$ in diameter). Clusters of small vesicles (up to $0.1 \mathrm{~mm}$ ) are scattered between the large ones.
The vesicle size distribution (VSD in Fig. 4) histograms are characterized by a decrease in percentage of vesicles from the golden pumice to the lava as well as an increase in coalescence and or expansion signatures in the spiny fragments, marked by the increase in the large-vesicle population (Fig. $4 \mathrm{c}$ and d). This trend is also marked by the decrease in number of vesicles per unit of volume $\left(N_{\mathrm{v}}\right.$, Fig. 4) from the golden pumice to the lava. Finally, the trend is also mirrored by the total percentage of crystals (calculated in 3D; Fig. 4 and reported for each sample in Table S3) that increases with the increase in density of the clasts, from a minimum of $7 \mathrm{vol} . \%$ for the golden pumice up to $49 \mathrm{vol} . \%$ for the spiny opaque scoria and 100 vol. \% for the lava (Fig. 4). Mesocrystals, formed mostly by plagioclase and clinopyroxenes, are absent or very scarce in the golden and fluidal fragments, while they reach their maximum values, up 5 vol. \%, in the spiny opaque fragment. The population of microcrystals, mostly constituted by plagioclases, ranges from a minimum of 8 vol. $\%$ in the golden pumice, up to $45 \mathrm{vol} . \%$ in the spiny fragments and $94 \mathrm{vol} . \%$ in the lava.

The connectivity data (Fig. 6c) also indicate that the fluidal and golden clasts have a larger number of isolated vesicles (up to $40 \mathrm{vol} . \%$ ) with respect to the spiny products. The fluidal clasts from the WF are the most homogeneous with an average percentage of isolated vesicles around $30 \mathrm{vol} . \%$. In contrast, both the pumice and the fluidal fragments from the MV, characterized by higher values of porosity ( $>75 \%$ ), have a wide range in percentage of isolated vesicles (between 20 and a few vol. \%). The fragments of the bomb collected at the UF are consistent with a vesiculated core characterized by scarce isolated vesicles and the quenched rind that has 30 vol. \% of isolated vesicles. Finally, the spiny fragments have the lowest content of isolated vesicles $(0-5$ vol. \%). Despite the presence of these isolated vesicles, all the samples shear high values of permeability, with the Darcian (viscous, $K_{1}$ ) permeability values ranging from $10^{-11}$ to $10^{-10} \mathrm{~m}^{2}$ (Fig. 6d and Table S3). The graph of vesicularity versus $K_{1}$ shows a slight increase in permeability with vesicularity, with the golden pumice being the most permeable among the samples and the spiny glassy fragment the least permeable. The three samples collected from the February 2015 eruption fit this trend. However, the densest spiny opaque scoria of the 2014 eruption share the high permeability value of the golden pumice.

\subsection{Chemistry of the products}

Major and trace element concentrations of whole-rock and hand-picked glass samples are reported in Table S4. Wholerock major element composition is very uniform (e.g. $6.5<\mathrm{MgO}<6.7 \mathrm{wt} \%$ ) and well within the range of steadystate basalts (SSBs), the most common type of basalts erupted at PdF (Albarède et al., 1997). However, compatible trace elements, such as $\mathrm{Ni}$ and $\mathrm{Cr}$, are at the lower end of the concentration range for SSB $(<100 \mathrm{ppm})$, indicat- 
ing that the June 2014 eruption sampled relatively evolved melts. $\mathrm{Ni}$ and $\mathrm{Cr}$ generally show higher concentrations in 2014 bulk rocks $(79<\mathrm{Ni}<92 \mathrm{ppm}$ and $71<\mathrm{Cr}<87 \mathrm{ppm})$ compared to the 2014 glass chips $(66<\mathrm{Ni}<73 \mathrm{ppm}$ and $54<\mathrm{Cr}<59 \mathrm{ppm}$ for all but two chips). In the $\mathrm{Cr}$ vs. Ni plot (Fig. 7a), whole rocks plot to the right of the main clinopyroxene \pm plagioclase-controlled melt differentiation trend. This shift reflects the addition of Ni-rich olivine (Albarède and Tamagnan, 1988). We estimate that the $\mathrm{Ni}$ excess results from the occurrence of a low amount $(0.7$ to $1.3 \mathrm{wt} \%)$ of cumulative olivine in whole rocks, consistent with thin section observations. The composition of olivine macrocrysts (ca. $\mathrm{Fo}_{84}$ ) is too magnesian to be in equilibrium with the low$\mathrm{MgO}$ evolved composition of the 2014 magma. Using our estimate for the amount of cumulative olivine, we recalculate the olivine-corrected $\mathrm{MgO}$ content of the 2014 magma at $6.2 \mathrm{wt} \%$. The June 2014 melt is thus only moderately depleted in compatible elements compared to the previous eruption of December $2010(\mathrm{MgO} \sim 6.6 \mathrm{wt} \%, \mathrm{Ni} \sim 80 \mathrm{ppm}$, $\mathrm{Cr} \sim 120 \mathrm{ppm})$. Conversely, the June 2014 melt is significantly depleted in compatible elements compared to the earlier November 2009 eruption, which sampled relatively primitive magmas (average $\mathrm{MgO} \sim 7.7 \mathrm{wt} \%, \mathrm{Ni} \sim 135 \mathrm{ppm}$, $\mathrm{Cr} \sim 350 \mathrm{ppm}$ ) (Fig. 7a). The 2014 evolved composition plots at the low Ni-Cr end of the PdF historical differentiation trend (Albarède and Tamagnan, 1988), near the composition of lavas erupted on 9 March 1998 after 5.5 years of quiescence (1992-1998). Note that olivine accumulation at PdF generally occurs in melt with ca. 100 ppm Ni (Albarède and Tamagnan, 1988). Olivine accumulation in evolved melts $(\mathrm{Ni}<70 \mathrm{ppm})$ seems to be a distinctive feature of many small post-2007 eruptions (e.g. this event and the three 2008 eruptions; see Di Muro et al., 2015).

A closer inspection of Ni-Cr variability in June 2014 whole-rock samples (Fig. 7b) reveals that scoria from the WF (140624-9b-6, Table S4) and early erupted lavas (1406$21-1$, Table S4) have the lowest amount of olivine $(<0.9 \%)$ whereas scoria from the UF (140624-13a) and late erupted lavas (140324-12) have a slightly higher amount of olivine $(>1.2 \%)$. This is consistent with the general trends observed at $\mathrm{PdF}$ of olivine increase from the start to end of an eruption (Peltier et al., 2009).

The so-called "olivine control trend" in $\mathrm{Ni}-\mathrm{Cr}$ space cannot be explained by either addition of pure olivine, which contains less than 500 ppm Cr (Welsch et al., 2009; Salaün et al., 2010; Di Muro et al., 2015), or by the addition of olivine plus pyroxene (which would require ca. $50 \%$ pyroxene with 970 ppm Ni and 4800 ppm Cr; see Fig. 7 caption). Instead, addition of olivine hosting ca. $1 \% \mathrm{Cr}$ spinel (with $25 \mathrm{wt} \%$ $\mathrm{Cr}$ ) accounts for data and observations and is consistent with crystallization of olivine and $\mathrm{Cr}$ spinel in cotectic proportions (Roeder et al., 2006). The fact that some samples (golden pumice) plot off the main well-defined array can be explained by either addition of more or less evolved olivine crystals (within the range of Fo80--85 measured in June 2014 sam- ples) and/or slight variations $( \pm 0.02 \%)$ in the proportion of Cr spinel (Fig. 7b).

The glass chemistry of the four clast types allows us to correlate porosity and oxide contents and shows an increase in $\mathrm{MgO}$ from the spiny opaque to fluidal and golden fragments (Fig. 8a). Consistent with petrological and textural observations, the spiny opaque is the most heterogeneous type of clast in terms of glass composition (Fig. 8). The glassy portion at the edge of the clast is similar to the spiny glass, while the interior, characterized by dark areas rich in tiny fibrous microcrysts, shows scattered glass compositions with very low $\mathrm{MgO}$ content as well as a decrease in $\mathrm{CaO}$ (Fig. 8). We attribute the significant variation in glass composition within the different components to variable degrees of microcrystallization as the bulk chemistry of all clasts is very similar and globally homogeneous.

\subsection{Melt inclusions}

MI analyses must be corrected for post-entrapment host crystallization at the MI-crystal interface. We used a $\mathrm{Kd}=$ $(\mathrm{FeO} / \mathrm{MgO})_{\mathrm{ol}} /(\mathrm{FeO} / \mathrm{MgO})_{\text {melt }}=0.306$ (Fisk et al., 1988; Brugier, 2016) and an average $\mathrm{Fe}^{3+} / \sum \mathrm{Fe}_{\text {total }}$ ratio of 0.11 (Bureau et al., 1998a; Di Muro et al., 2016 and references therein) defined for PdF magmas. For the June 2014 melt inclusions, the post-entrapment crystallization ranges from 2.9 to $10.5 \mathrm{wt} \%$. Raw and corrected major and volatile element concentrations of MIs are reported in Table S6.

Host olivines span a large compositional range from $\mathrm{Fo}_{80}$ to Fo86. Despite the evolved bulk composition of the magma, most olivines are quite magnesian (Fo83-85) and are not in equilibrium with the evolved host magma. Conversely, Mg-poor olivines (Fo80-81) can be considered as being in equilibrium with the bulk rock composition. The corrected compositions of MIs in phenocrysts from the different samples partly overlap with the evolved bulk rocks $\left(\mathrm{MgO}_{\mathrm{wr}}\right.$ : 6.1-7.2 wt \%) and extend to higher $\mathrm{MgO}$ contents of up to $8.8 \mathrm{wt} \%$ (Table S6). MIs display a narrow range of transitional basaltic compositions $\left(\mathrm{K}_{2} \mathrm{O}=0.5-0.9 \mathrm{wt} \%\right)$ and show no significant difference between the three types of scoriae. The major element composition of MIs correlates with that of the host olivines. MIs in the high Fo olivines have the highest $\mathrm{MgO}, \mathrm{CaO}$ and $\mathrm{TiO}_{2}$ and lowest $\mathrm{K}_{2} \mathrm{O}$ concentrations (Table S6). It is interesting to note that the June 2014 products contain two populations of magnesian $\left(\mathrm{Fo}_{>}\right.$83) olivines hosting MIs with two distinct Ca contents. Most of the magnesian olivines contain MIs with unusually high $\mathrm{CaO}$ contents (11.6-12.9 wt \%) and high $\mathrm{CaO} / \mathrm{Al}_{2} \mathrm{O}_{3}$ ratios (0.8-0.9), higher than those of the bulk rocks (0.8) (Fig. 8). The occurrence of olivines with high-Ca MIs has been observed in all three different types of scoriae. A few magnesian olivines and all $\mathrm{Mg}$-poor olivines (Fo80.5-83.6) host MIs with lower $\mathrm{CaO}$ contents $(11.4 \mathrm{wt} \%)$. This latter composition overlaps with that of the bulk rock (Fig. 8). The high-Ca population of inclusions is also enriched in $\mathrm{TiO}_{2}$ and $\mathrm{Al}_{2} \mathrm{O}_{3}$ and de- 
pleted in $\mathrm{MgO}, \mathrm{FeO}_{\mathrm{T}}$ and $\mathrm{Na}_{2} \mathrm{O}$ for a given olivine Fo content with respect to the low-Ca population. Both low- and high-Ca populations of MIs have similar $\mathrm{K}_{2} \mathrm{O}$ contents and total alkali content increases from 3 at $12.6 \mathrm{wt} \% \mathrm{CaO}$ to 3.5 at $10.8 \mathrm{wt} \% \mathrm{CaO}$. However, we remark that high-Ca MIs from the June 2014 activity record a significant scattering in $\mathrm{K}_{2} \mathrm{O}$ contents, which range from 0.55 to $0.9 \mathrm{wt} \%$. These anomalous compositions potentially track processes of crystal dissolution (e.g. pyroxene dissolution).

MIs in olivines from June 2014 can best be compared with those of other recent small-volume and short-lived eruptions that emitted basalts with low phenocryst contents, like those in March $2007\left(0.6 \times 10^{6} \mathrm{~m}^{3}\right)$ and November 2009 $\left(0.1 \times 10^{6} \mathrm{~m}^{3}\right)$ (Roult et al., 2012). March 2007 aphyric basalt has a bulk homogeneous composition with intermediate $\mathrm{MgO}$ content $\left(\mathrm{MgO}_{\mathrm{wr}}: 7.33 \mathrm{wt} \% ; \mathrm{K}_{2} \mathrm{O}: 0.67 \mathrm{wt} \%\right)$. Their olivines $\left(\mathrm{Fo}_{81}\right)$ are in equilibrium with the bulk rock and their composition is unimodal (Di Muro et al., 2014). November 2009 products are the most magnesian lavas emitted in the 2008-2014 period; they are slightly zoned $\left(\mathrm{MgO}_{\mathrm{wr}}\right.$ : 7.6-8.3 wt \%; $\left.\mathrm{K}_{2} \mathrm{O}: 0.75-0.62 \mathrm{wt} \%\right)$ and contain a few percent of normally zoned olivine macrocrysts with bimodal composition (Fo81 and $\mathrm{Fo}_{83.5}$; see Di Muro et al., 2016). June 2014 bulk rocks $\left(\mathrm{MgO}_{\mathrm{wr}}: 6.7 \mathrm{wt} \% ; \mathrm{K}_{2} \mathrm{O}: 0.75 \mathrm{wt} \%\right)$ and MIs in Fo $80-81$ olivines are quite evolved. Their composition is close to that of products emitted by summit intracaldera eruptions in 2008, ca. 1.5 years after the large 2007 caldera-forming eruption (Di Muro et al., 2015) (Fig. 8). As already reported for 2008 products, many olivine macrocrysts of 2014 are clearly too magnesian to be in equilibrium with the relatively evolved host melts. Overall, $\mathrm{MgO}$ content in 2007-2014 MIs tends to decrease with decreasing Fo content of the host olivines. MIs in olivines also exhibit a trend of linear decrease in $\mathrm{MgO}$ and increase in $\mathrm{FeO}$ from April 2007 to 2009-2014 products (Fig. 9). MIs in March 2007, November 2009 and June 2014 follow the same trend of $\mathrm{FeO}$ enrichment (Fig. 9). In the large-volume and olivine-rich April 2007 products, MIs in magnesian olivines with $\mathrm{Fo}_{>} 82$ have distinctly higher $\mathrm{MgO}$ and $\mathrm{FeO}$ and lower $\mathrm{SiO}_{2}$ and $\mathrm{Al}_{2} \mathrm{O}_{3}$ than MIs in 2009-2014 products. The distinctive $\mathrm{FeO}$ enrichment of many of the MIs from the April 2007 oceanite has been interpreted by Di Muro et al. (2014) as a result of post-entrapment modification related to new magma inputs into long-lasting magma storage.

Two populations of low- and high-Ca MIs are also found in the November 2009 olivines. Low-Ca melt inclusions from the November 2009 and June 2014 eruptions indicate a single trend of chemical evolution (Fig. 8), consistent with bulk rock compositions. June 2014 products have lower $\mathrm{MgO}$ and $\mathrm{CaO}$ contents than those from November 2009. Significant scattering in $\mathrm{K}_{2} \mathrm{O}$ content $(0.6-0.9 \mathrm{wt} \%)$ is found in low$\mathrm{Ca}$ inclusions from 2009, as observed in high-Ca inclusions from the 2014 eruption, but they share similar $\mathrm{K}_{2} \mathrm{O}$ contents. In the 2009 and 2014 products, $\mathrm{K}_{2} \mathrm{O}$ content of MIs is partly anti-correlated with the olivine Fo content. This ob- servation has been attributed to moderate heterogeneity of primary melts feeding the plumbing system of PdF. Rapid temporal changes of $\mathrm{K}_{2} \mathrm{O}$ content in PdF basalts have been reported (Boivin and Bachélery, 2009).

\subsection{Mineral composition and glass - plagioclase equilibrium}

All 2014 scoriae (spiny, fluidal, golden) contain the same paragenesis of olivine, clinopyroxene and plagioclase. The composition of minerals found in golden, fluidal and spiny scoriae is indistinguishable.

In olivines, average $\mathrm{MgO}$ content decreases from macrocrysts (Fo84.1) to mesocrysts (Fo79.6) to microcrysts. Olivine microcrysts (Table S5) are normally zoned. Their composition ranges from Fo $78.0-75.3$ in the cores to Fo $74.3-70.5$ in the rims. Overall, olivines in 2014 products span the full range of typical Fo contents of recent PdF magmas (Boivin and Bachèlery, 2009; Di Muro et al., 2014, 2015). Clinopyroxene composition (augites) ranges from $\mathrm{En}_{53} \mathrm{Fs}_{15} \mathrm{Wo}_{32}$ to $\mathrm{En}_{41} \mathrm{Fs}_{14} \mathrm{Wo}_{45}$. Their average composition $\left(\mathrm{En}_{45} \mathrm{Fs}_{14} \mathrm{Wo}_{41}\right)$ is consistent with that found in other evolved melts like those emitted by the 2008 eruptions ( $\mathrm{Di}$ Muro et al., 2015) and more generally in recent PdF products (Boivin and Bachèlery, 2009). Clinopyroxenes are unzoned; the composition of cores and rims is very similar and close to that found in microcrysts and mesocrysts. Plagioclase composition ranges from $\mathrm{An}_{79.5} \mathrm{Ab}_{19.9} \mathrm{Or}_{0.6}$ to $\mathrm{An}_{63.1} \mathrm{Ab}_{35.7} \mathrm{Or}_{1.2}$ with a bimodal distribution $\left(\mathrm{An}_{76.5-79.5}\right.$ and $\mathrm{An}_{63.1-72.9}$, Fig. 10a). Similar bimodal distributions were observed in many other products at PdF (Di Muro et al., 2015). Mesocrysts $\left(\mathrm{An}_{75.5} \mathrm{Ab}_{23.8} \mathrm{Or}_{0.7}\right.$ on average) are more calcic with respect to microcrysts $\left(\mathrm{An}_{65.7} \mathrm{Ab}_{33.1} \mathrm{Or}_{1.2}\right.$ on average). Normal zoning is found from plagioclase cores to rims (Fig. 10a). The composition and zonation of 2014 plagioclases clearly contrast with the complex and often reverse zoning patterns and intermediate composition of the $2008 \mathrm{PdF}$ products that were attributed to pre-eruptive magma heating (Di Muro et al., 2015).

Plagioclase-melt equilibrium and melt composition in pyroclastic rocks and water-quenched lavas were used to estimate both temperature and water content dissolved within the melt (Fig. 10b and Table S5). Temperature estimates are based on the (dry) equation of Helz and Thornber (1987) recalibrated by Putirka (2008). Dissolved water content was calculated from the plagioclase hygrometer of Lange et al. (2009) at $50 \mathrm{MPa}$. This pressure corresponds to the average $\mathrm{CO}_{2}-\mathrm{H}_{2} \mathrm{O}$ saturation pressure (recalculated with Papale et al., 2006) typically recorded in MIs from central products at PdF (e.g. 1931 eruption in Di Muro et al., 2016, and references therein). This pressure roughly corresponds to the sea level depth, which is inferred to be the location of the potential main shallow magmatic reservoir (Peltier et al., 2009; Lengliné et al., 2016; Coppola et al., 2017). The application of the plagioclase hygrometer of Lange et al. (2009) 
makes it possible to estimate the dissolved water content in the melt with a nominal uncertainty of $0.15 \mathrm{wt} \%$ and is only slightly dependent on pressure. Plagioclase compositions not in equilibrium with the melt (glass or bulk rock) are those of mesocryst cores with the highest $\left(\mathrm{An}_{>} 76.5\right)$ anorthite content (Fig. 10a and Table S5). Such compositions are more in equilibrium with $\mathrm{CaO}$-richer magnesian melts than those measured in matrix glasses and bulk rocks of the 2014 eruption and likely formed during early stages of shallow magma differentiation (Fig. 10a).

In order to determine pre-eruptive conditions, calculations were performed only on paired plagioclase rims and matrix glasses in equilibrium, using the plagioclase-melt equilibrium constant of Putirka (2008) calibrated for melts whose temperature exceeds $1050^{\circ} \mathrm{C}\left(\mathrm{Kd}_{\mathrm{An}-\mathrm{Ab}}=0.27 \pm 0.05\right)$. Our review of published and unpublished data shows that melt temperature progressively decreases from April 2007 $\left(1188 \pm 16^{\circ} \mathrm{C}\right)$ to January-October $2010\left(1147 \pm 9^{\circ} \mathrm{C}\right)$ and positively correlates with $\mathrm{K}_{2} \mathrm{O}$ content in melts, which increases from 0.70 to $0.96 \mathrm{wt} \%$ (Fig. 10b). The melts from the June 2014 eruption record the lowest temperatures in post-2007 eruptions $\left(1131 \pm 15^{\circ} \mathrm{C}\right)$ together with the highest $\mathrm{K}_{2} \mathrm{O}$ enrichment $\left(\mathrm{K}_{2} \mathrm{O}: 0.90 \pm 0.12 \mathrm{wt} \%\right)$. The lowest temperatures are recorded by spiny scoriae, while the temperature of golden scoriae overlaps with that of 2010 products emitted before the 2010-2014 phase of quiescence. In spite of the large variability in melt composition and temperature, average pre-eruptive water content dissolved in the melts $(0.5 \pm 0.2 \mathrm{wt} \%)$ is quite homogeneous for the whole 2008-2014 period. In 2014, the lowest estimated dissolved water content (down to $0.38 \mathrm{wt} \%$ ) is for the golden and some fluidal scoriae, while the maximum amount $(0.68 \mathrm{wt} \%)$ is for the spiny opaque scoriae. However, water content estimated from core-bulk rock equilibrium $(0.3 \pm 0.1 \mathrm{wt} \%)$ is slightly lower than that estimated from rim and microlitematrix glass equilibrium $(0.5 \pm 0.2 \mathrm{wt} \%)$, but the difference broadly overlaps the nominal uncertainty related to calculations. Dissolved water contents in melts of the pyroclasts are thus intermediate between those measured in 2007 melt inclusions $\left(\mathrm{H}_{2} \mathrm{O}: 0.8 \pm 0.15 \mathrm{wt} \%\right.$ and up to $\left.1.1 \mathrm{wt} \%\right)$ and those typically found in degassed matrices of lava and Pele's hairs of 2007 (Fig. 10b; 0.2 wt \%; see Di Muro et al., 2015, 2016).

\section{Discussions}

\subsection{Eruptive dynamics}

The activity fed by the uppermost WF and UF (Fig. 1) was very short-lived, as shown by the presence of only scattered bombs and coarse lapilli (Fig. 3d and e). The homogeneity of these clasts, their coarsely grained nature and the fluidal smooth texture are in agreement with very short-lived fire fountaining and magma jets. Glassy outer surfaces of clasts have been interpreted as a late-stage product of fusion by
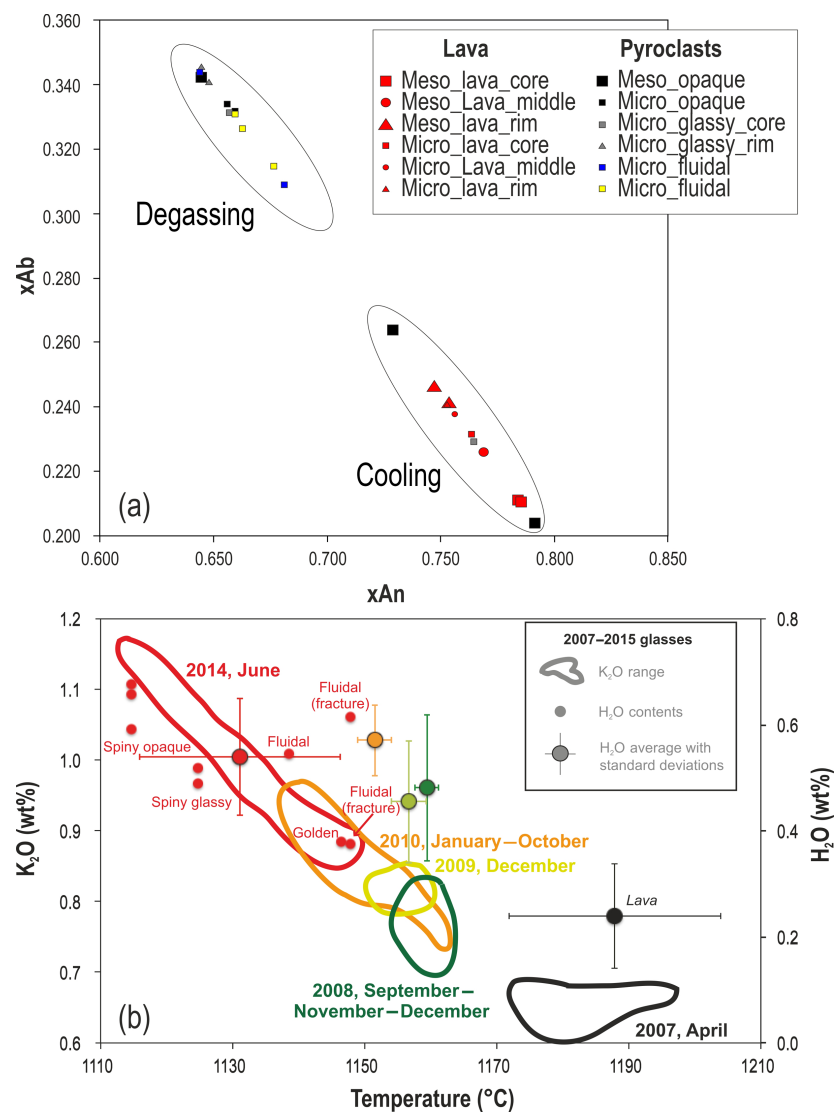

Figure 10. (a) Anorthite versus albite compositions for the plagioclase crystals measured for the June 2014 eruption of PdF. (b) Temperature, composition $\left(\mathrm{K}_{2} \mathrm{O}\right)$, and dissolved water content $\left(\mathrm{H}_{2} \mathrm{O}\right)$ for the evolution of 2007-2014 melts from glasses. The data have been obtained by studying the glass-plagioclase equilibrium or on the basis of matrix glass analyses. Temperature estimation based on the $\mathrm{MgO}$ thermometer of Helz and Thornber (1987) modified by Putirka (2008). Water content is from the plagioclase hygrometer of Lange et al. (2009). Only plagioclases in equilibrium with melts are considered, following the procedure described by Putirka (2008) for $>1050{ }^{\circ} \mathrm{C}$ melts $(\mathrm{Kd}=0.27 \pm 0.05)$. Error bars reported in Fig. $10 \mathrm{~b}$ correspond to the standard deviation of the plagioclase dataset, whose range is larger than the error of the method. We stress that the reported temperatures are obtained using the Helz dry model. Further uncertainty arises from the dependence of the method on dissolved water content as shown recently by Putirka (2008). In order to minimize the number of assumptions and perform a comparison between distinct eruptions, we preferred the dry model.

hot gases streaming past the ejecta within the jet or fountain (Thordarson et al., 1996; Stovall et al., 2011). However, the occurrence of this process is not supported by the homogeneous glass composition in our fluidal clasts. Therefore, we interpret these features here just as rapid quenching and not re-melting. Vlastélic et al. (2011) documented the mobility of alkalis and other elements on PdF clasts that experienced long exposures to acid gases. In the 2014 eruption pyroclasts, 
the mobility of elements was prevented by the short duration of the events.

At lower altitude and close to the MV (Fig. 1), the $5 \mathrm{~cm}$ layer at the base of the fall deposit is finely grained (Fig. 3b and c) and rich in fluidal and golden fragments (Fig. 5), with a perfect Gaussian grain size curve (Fig. 5), and similar to that reported from the weak 2010 fountaining event (Fig. $3 f$ and Hibert et al., 2015). Therefore, we interpret this deposit as being due to weak Hawaiian-like fountaining (sustained, but short-lived) activity. We want to remark here that this activity happened during the night and was not observed. The top of the same deposit is coarsely grained (Fig. 3b and c), bimodal, has a lower content in coarse ash (Table S2) and is rich in spiny opaque and spiny glass fragments (Fig. 5). The reverse grain size likely records the transition from early continuous fountaining to late discrete Strombolian activity (observed and recorded on the 21 of June 2014, Fig. 2). This transition in activity is typical of many eruptions at PdF (Hibert et al., 2015). The reverse grading of the whole deposit (Fig. 3b and c) is thus not correlated with an increase in energy of the event but with two different eruptive dynamics and fragmentation processes. The decrease in coarse ash, which correlates with the decrease in energy of the event, highlights the most efficient fragmentation process within the Hawaiian fountaining with respect to the slow gas ascent and explosion of the Strombolian activity. These conclusions are consistent with (i) the continuous and progressive decrease in intensity of real-time seismic amplitude measurement recorded by the OVPF seismic network (unpublished data) and (ii) satellite-derived time-averaged lava discharge rates, which suggest continuous decay of magma output rate after an initial short-lived intense phase (Coppola et al., 2017).

\subsection{Background on the texture of clasts from Hawaiian and Strombolian activities}

The first micro-textural analysis of Hawaiian ejecta was performed by Cashman and Mangan (1994) and Mangan and Cashman (1996) on pyroclasts from 1984 to $1986 \mathrm{Pu}$ 'u ' $\mathrm{O}^{\prime} \overline{\mathrm{o}}$ fountainings. The authors defined two clast types: (1) scoria consisting of closed-cell foam of $\leq 85 \%$ vesicularity, with round, undeformed, broadly sized vesicles and (2) reticulite, an open-cell polyhedral foam with $\sim 1 \mu \mathrm{m}$ thick vesicle walls with $>95 \%$ vesicularity. They stated that the scoriato-reticulite transition is a consequence of Ostwald ripening, where larger bubbles grow at the expense of smaller bubbles due to post-fragmentation expansion of clasts within the fountain. According to this model, scoria preserves textures closer to conditions at fragmentation, whereas continued vesiculation and clast expansion in the thermally insulated core of the fountain results in reticulite. This model was confirmed at lava fountains at Etna (Polacci et al., 2006), Villarrica (Gurioli et al., 2008), Kīlauea Iki, (Stovall et al., 2011, 2012), Mauna Ulu (Parcheta et al., 2013) and Al-
Madinah (Kawabata et al., 2015). These last authors also measured the connected and isolated porosity in the AD1256 Al-Madinah Hawaiian fountaining eruptions. They found that the reticulite-like textures from the central part of these very high fountains showed isolated vesicles in agreement with low shear rates and low viscosity melts, where bubbles may grow spherically and remain isolated. In contrast, at margins of the fountains, high shear may lead to stretching and mechanical coalescence of bubbles, forming the common, fluidal types of particles also seen in the deposits. They also stated that lower vesicularity and greater isolated porosity were found in some tephra, interpreted as resulting from violent Strombolian eruptive phases.

The data that we found in our study of the typical activity of PdF agree only partially with all these interpretations. The reason is that we sampled and measured products of very weak Hawaiian to Strombolian activities. If we plot the approximate durations and masses of these events on the Houghton et al. (2016) diagram, the 2014 activity of PdF falls into the two fields for transient and fountaining activity, but at the base of the diagram. We here show for the first time that short-lived and weak fountaining can preserve pyroclast textures that record magma ascent and fragmentation conditions before the explosions and also provide some information about the pre-eruptive storage conditions. The occurrence of time-variable ascent conditions is also reflected in the time evolution of eruptive dynamics, with the golden and fluidal scoriae emitted from the low Hawaiian fountaining episodes and the spiny fragments from the Strombolian-like explosions.

\subsection{The four typologies of clasts and their distribution in space and in time in the 2014 eruption at PdF}

Thus, as described in Sect. 5.1, longitudinal variation in eruptive style along the fracture system produces a spatial variability in the proportions of the four typologies of clasts. The uppermost fractures (WF and UF, Fig. 1a) are characterized solely by fluidal fragments (Fig. 4b); they lack both the spiny and the golden components. In addition, these fluidal clasts are the ones showing the smoothest surfaces (indicative of rapid quenching in a very hot environment), low porosity values (between 50 and 77 vol. \%, Fig. 6b), the highest content in isolated vesicles $(\sim 30$ vol. $\%$, Fig. $4 \mathrm{c})$ and low vesicle numbers ( 3 to $5 \times 10^{6}$, Fig. $4 \mathrm{~b}$ ) comparable to the spiny fragments. They have scarce mesocrysts (1 vol. \%, Table S3) and a low number of microcrysts of plagioclase and clinopyroxene (11 to 12 vol. \%, Table S3). These fluidal scoria fragments were emitted by short-lived jets of magma; therefore they underwent rapid quenching in a very hot environment that prevented any expansion or further vesiculation and preserved a very high number of isolated vesicles (Fig. 6d). Syneruptive crystallization was hindered by high ascent velocities in the dike due to the sudden release of over-pressure in the shallow magma reservoir. 
The four typologies of clasts, golden pumice, fluidal scoria and the spiny fragments (Fig. 4) were only found at the MV. The relative proportions of these four typologies of clasts correlate with the eruptive dynamics. The golden lapilli and fluidal clasts were in fact dominant in the more energetic Hawaiian activity at the beginning of the eruption (during the night between 20 and 21 of June 2014). In contrast, the spiny fragments were dominant during the Strombolian activity, coinciding with the decrease in mass discharge rate (early in the morning of the 21; Fig. 2 and Coppola et al., 2017). The golden and fluidal fragments from the MV show the highest porosity ( $86 \%$, Fig. 6a), variable proportions of isolated vesicles (Fig. 6c) and high, but variable, $N_{\mathrm{v}}$ numbers (Fig. 4a). They are also characterized by a uniform vesicle size population with clear evidence of incipient expansion, especially in the fluidal fragments (Fig. $4 a$ and b). From the connectivity graph, there is a clear decrease in isolated vesicles with the increase in vesicularity (Fig. 6c). The content in crystal, mostly formed by microcrysts of sodic plagioclase (Fig. 10a) due to magma degassing during its ascent and decompression in the conduit (Di Muro et al., 2015), is very low, especially in the golden pumice (up to 9 vol. \%), and it is slightly higher for the fluidal clasts (up to $22 \mathrm{vol} . \%$ ). We interpret the golden fragments, at the MV, to be the fastest (low number of microcrysts) and less degassed magma (high vesicularity coupled with high $N_{\mathrm{v}}$ ), which experienced only a very short residence time in the magma transport system (dike + vent), followed by the fluidal fragments. In contrast the spiny fragments, characterized by a higher percentage of microcrysts and mesocrysts, by the lack of isolated vesicles, and by the presence of coalescence signature and low $N_{\mathrm{V}}$ values (Fig. $4 \mathrm{c}$ and d), are indicative of an extensively degassed and cooled magma. The presence of the mesocrysts (that formed in the shallow reservoir) in the spiny fragments, and their slightly cooler temperature (Fig. 10b), strongly support this interpretation. The spiny fragments likely record the slowest ascent velocity and the longest residence time in the reservoir + dike + vent system compared to the golden or fluidal counterpart. Therefore these fragments are associated with Strombolian events, and decreasing mass discharge rate, in agreement with their slower ascent that allows extensive syn-eruptive crystallization.

Among spiny fragments, the opaque ones are the densest; they lack a uniform glassy surface, and they are characterized by (i) very high microcryst content, (ii) strong coalescence signature (Fig. 4d), (iii) heterogeneous glass chemistry and (iv) mingling with hotter magma at the clast edges (Fig. 8a). All these features reveal the composite nature of these clasts. We interpret the spiny opaque as spiny glass fragments recycled inside the eruptive vent during the explosions, with the densest portion of the magma prone to falling back in the vent or fracture (Fig. 2b).

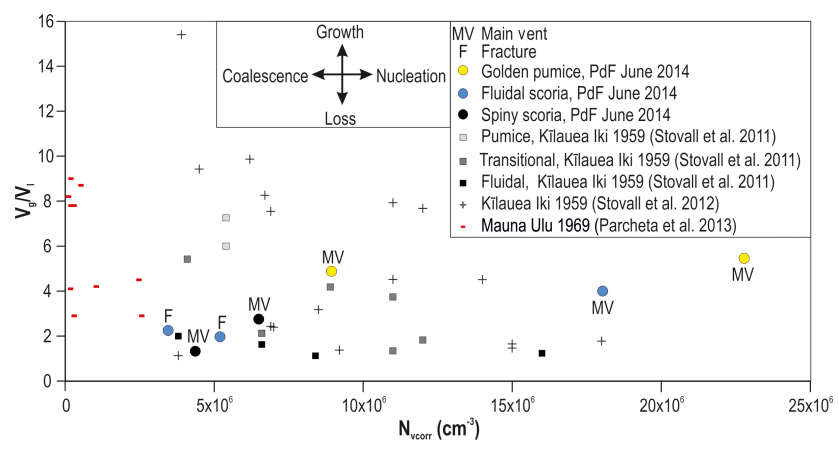

Figure 11. Volumetric ratio of vesicles to melt $\left(V_{\mathrm{g}} / V_{1}\right)$ versus vesicle number density.

\subsection{Degassing-driven versus cooling-driven crystallization}

Syn-eruptive degassing is favoured by bubble connectivity and/or permeability (Fig. 6c and d) in the ascending magma, enhanced by syn-eruptive crystallization in the conduit (especially microcrysts of plagioclase, Fig. 10a), even for magmas at low vesicularity. However, our dataset also supports the occurrence of magma stratification in the reservoir. Textural and petrological data demonstrate that the initial activity emitted a small volume of melt (represented by golden fragments and a large part of the fluidal fragments) with very scarce crystals. This crystal-poor melt was followed in time by the main volume of magma that contains a larger number of mesocrysts (spiny clasts and lava). Lava flows represent the main volume emitted in the 2014 eruption. Mesocrysts are absent in the golden, scarce in the fluidal, and more abundant in the spiny (Fig. 4b, c and d) and lava (Fig. 4e) fragments and consist in plagioclase and clinopyroxene and minor olivine. Their composition indicates that they formed in the reservoir, as shown by their different composition in respect to the microcryst counterparts that formed during melt degassing in the conduit (Fig. 10a). Most importantly, a large number of microcrysts in lava formed in the reservoir as well as during magma cooling (Fig. 10a). Thus, we have a range of crystallization conditions. The fact that the lighter plagioclase are not concentrated in the upper and early erupted portion of the reservoir can be due either to the fact that often they are locked in clusters with the clinopyroxene or that this melt was expelled from the crystal-rich portion of the reservoir (see Fig. 10b). Water exsolution from the melt can result from its extensive crystallization, which induces an increase in dissolved volatile content, up to saturation (second boiling) and can drive melt-crystal separation.

In conclusion, the crystals in the 2014 fragments do reflect the shallow reservoir conditions and the ascent degassing processes. 


\subsection{Textural syn-eruptive versus post-fragmentation modifications}

To prove that the 2014 vesiculation of the clasts has not been modified by post-fragmentation expansion processes, following Stovall et al. (2011), we use a plot of vesicle-tomelt ratio $\left(V_{\mathrm{g}} / V_{1}\right.$; after Gardner et al., 1996) and vesicle number density $\left(N_{\mathrm{b}}\right.$, Fig. 11). As demonstrated by Stovall et al. (2011), the addition of small bubbles leads to an increase in $N_{\mathrm{v}}$ and only a slight increase in $V_{\mathrm{g}} / V_{1}$. Bubble growth by some combination of diffusion and decompression leads to an increase in $V_{\mathrm{g}} / V_{1}$ at constant $N_{\mathrm{v}} . N_{\mathrm{v}}$ decreases while $V_{\mathrm{g}} / V_{1}$ increases during bubble coalescence, whereas loss of bubbles via collapse or buoyant rise leads to a reduction in both parameters. Intermediate trends on the diagram reflect combinations of more than one of these processes. The pumice and the scoria from the MV of PdF show the highest $V_{\mathrm{g}} / V_{1}$ but also the highest $N_{\mathrm{v}}$, suggesting preservation of small vesicles and growth by some combination of diffusion and decompression. The presence of the small vesicles and the lack of a strong coalescence and/or expansion signature confirm that the weak PdF activity leads to only limited post-fragmentation expansion inside the hot portions of the short-lived fountains. These data contrast with the data from the more energetic fountaining events observed at Kîlauea or elsewhere, where pre-eruptive information is basically erased because pumice textures are dominated by expansion effects due to their longer residence within the long-lived energetic fountaining. In contrast, the densest, spiny scoriae and the scoriae from the fractures activity show the lowest values of $N_{\mathrm{v}}$ and $V_{\mathrm{g}} / V_{1}$ due to incipient coalescence and/or loose or lack of small bubbles.

According to previous works (listed above), the golden pumice of PdF should be derived from the central part of the fountains, but they do not show the strong post-expansion signatures reported by other samples collected from more energetic Hawaiian fountainings (Fig. 11). It is interesting to note that the fluidal fragments at the MV are less smooth (Fig. 4), more vesiculated and have a lower content of isolated vesicles than the fluidal scoriae from the uppermost fractures (Fig. 6). Therefore fluidal fragments at the 2014 MV could indeed represent clasts that have been partly modified during their residence in the external part of the fountains, while the golden samples could come from the central part (Stovall et al., 2011, 2012). However, the slight differences in crystallinity and glass chemistry between the fluidal and golden fragments support the idea that each of these fragments has an imprint from the pre-fragmentation setting. In contrast, the spiny fragments from the MV and the fluidal fragments from the fractures show low $N_{\mathrm{v}}$ and low $V_{\mathrm{g}} / V_{1}$ in agreement with loss of vesicles and coalescence. However, the presence of large numbers of isolated vesicles within the fluidal scoriae from the fractures agrees with their provenance from a fast, hot ejection of relatively degassed magma (low $N_{\mathrm{v}}$ ). In contrast, the spiny fragments, especially because of the presence of mesocrysts and an increase in syn-eruptive microcrysts, are indicative of the slowest ascent velocity and extensive degassing and cooled magma. The spiny fragments are the most degassed, densest and the most crystal-rich magma that was emitted during low-energy activity by Strombolian explosion, where recycling phenomena were also very frequent (Fig. 2f).

Our vesicle connectivity results are in full agreement with the recent review of Colombier et al. (2017b). According to these authors, connectivity values can be used as a useful tool to discriminate between the basaltic scoriae from Hawaiian (fire fountaining) and Strombolian activity. The broad range in connectivity for pumice and scoriae from fire fountaining is interpreted simply as being due to variations in the time available before quenching due to differences in location and residence time inside the fountain. The fluidal fragments from the WF are the richest in isolated vesicles because they are transported by very short-lived hot lava jets. In contrast, the higher connectivity observed in scoriae from Strombolian activity is probably related to their higher average crystallinity and more extensive degassing prior to the eruption (Colombier et al., 2017b). The spiny surface of these Strombolian fragments is due to the fact that these weak explosions emit only a small solid mass fraction and the partially quenched dense clasts land quickly after a short cooling path through the surrounding atmosphere (e.g. Bombrun et al., 2015).

All the clasts, from golden to spiny, are very permeable, independent on their vesicularity, crystal content and/or of the presence of isolated vesicles. This is in agreement with our interpretation that magma degasses during its ascent in the conduit and that promotes microlite nucleation (see the sodic plagioclase, Fig. 10a) before magma fragmentation (see also Di Muro et al., 2015, with the Pele's hair and tear samples for the three 2008 eruptions). Moreover, we always find that some of the spiny clasts (especially the opaque ones) are slightly less permeable than the golden and fluidal ones, but not with a low permeability as we would expect from their low vesicularity.

In conclusion, we can state that (i) the crystals lower the percolation threshold and stabilize permeable pathways and (ii) this is true for the syn-eruptive sodic plagioclase that favour an efficient degassing in the relatively crystalrich magma because of their low wet angles that favour degassing over nucleation (Shea, 2017) and their aspect ratio (e.g. Spina et al., 2016). (iii) Therefore permeability develops during vesiculation through bubble coalescence, which allows efficient volatile transport through connected pathways and relieves over-pressure (Lindoo et al., 2017). Pervasive crystal networks also deform bubbles and therefore enhance outgassing (Oppenheimer et al., 2015). Based on Saar et al. (2001) crystals should start to affect the behaviour of the exsolved volatile phase when they approach 20 vol. \% (Lindoo et al., 2017). In our dataset, apart from the golden and part of the fluidal fragments, all the other clasts do have mi- 
crocrysts $>20 \%$. Our data completely support slow decompression rate allowing more time for degassing-induced crystallization, which lowers the vesicularity threshold at which bubbles start to connect.

Rapid re-annealing of pore throats between connected bubbles can happen due to short melt relaxation times (Lindoo et al., 2016). This phenomenology could explain the high number of isolated vesicles in the fountaining samples. However, vesicle distributions of the golden and fluidal fragments are almost perfect Gaussian curves, so it seems that if the relaxation process does occur then it just merged perfectly with the expected vesicle distribution. In contrast, coalescence and/or expansion (as we observe in the spiny fragments) do not fit the curves (Fig. 4). In addition, we should expect that in crystal-poor fragments, due to melt relaxing and pathway closure, the clasts became almost impermeable after quenching, as revealed by some petrological experiments performed on crystal-poor basaltic magma (Lindoo et al., 2016). In contrast, in high crystalline magmas, the presence of micro-crystals increases viscosity, thus preserving the coalesced textures (see Moitra et al., 2013). The isolated vesicle-rich fragments of the $2014 \mathrm{PdF}$ eruption are highly permeable and are characterized by variable ranges of porosity and numbers of vesicles (Figs. 4 and 6d) that seem more related to the pre-eruptive conditions than to the postrelaxation of low-viscosity melts. In the 2014 crystal-poor samples, the permeability increases rapidly once the percolation threshold has been reached, and efficient degassing prevents bubble volumes from expanding past the percolation threshold (Rust and Cashman, 2011).

In conclusion, the vesicles in the 2014 fragments do also partly reflect the shallow reservoir conditions and mostly the ascent degassing processes.

\subsection{Integration between the physical and textural characteristics of the products and their geochemical signature: insight into the feeding system}

According to Peltier et al. (2016), the June 2014 eruption emitted magma from a shallow pressurized source located only $1.4-1.7 \mathrm{~km}$ below the volcano summit. Coppola et al. (2017) suggest that the 2014 event was fed by a single shallow and small-volume magma pocket stored in the uppermost part of the PdF central plumbing system. All 2014 clasts show homogeneous and evolved bulk compositions, irrespective of their textural features. June 2014 products are among the most evolved products erupted since at least 1998 and are moderately evolved with respect to those emitted in 2010, just before the 2010-2014 quiescence. Bulk rock and MI data suggest that the 2014 evolved magma can be produced by crystal fractionation during the long-lasting (4.6 yr) storage and cooling of the magma injected and partly erupted in November 2009. The different types of scoria and pumice emitted in 2014 show significant variations in glass composition (Fig. 8b) due to variable degrees of microcrystallization. In theory, microcrysts can reflect late-stage (during magma ascent and post-fragmentation) crystallization. In this case, their variable amount within, for instance, the glassy and opaque parts of the spiny scoria might reflect slower ascent velocity or longer residence time in the system (e.g. Hammer et al., 1999; Stovall et al., 2012; Gurioli et al., 2014) also in agreement with the vesicle signature. However, the four typologies of clasts also differ in terms of mesocryst content (from rare to $5 \mathrm{vol} . \%$ for the golden and fluidal and $14-23$ vol. \% for the glassy spiny and spiny opaque). Equilibrium plagioclase-melt pairs record an almost constant and moderate dissolved water content, intermediate between that expected for melts sitting in the main shallow reservoir (located close to sea level) and the degassed matrix of lavas. Dissolved water contents are thus consistent with pre-eruptive magma water degassing during its storage at a shallow level, as suggested by geophysical data, and suggest that the plagioclase mesocrysts and some of the microcrysts in the spiny scoria and in the lava grew during magma storage (Fig. 10a). Melt composition records a potential pre-eruptive thermal gradient of $\sim 30^{\circ} \mathrm{C}$ between the hotter (pumice and fluidal) and the cooler (spiny) magma (Fig. 10b).

Tait et al. (1989) suggest that magma evolution can lead to oversaturation of volatile species within a shallow reservoir and trigger a volcanic eruption. At PdF, the golden and the fluidal clasts might represent the portion of magma located at the top of the shallow reservoir and enriched in bubbles of water-rich fluids, released by the cooler, more crystallized and more degassed "spiny lava" magma (Fig. 10b). The small volume of magma, its constant bulk composition and the very small inflation recorded prior to the eruption (Fig. 1d) could be consistent with an internal source of over-pressure related to volatile exsolution. Larger inflation rates over a broader area are expected when shallow reservoir pressurization is related to a new magma input from a deeper source. Slight baseline extensions both on distal and proximal sites suggest that magma transfer towards shallower crustal levels started shortly before (11 days) the final magma eruption. Geochemical data do not support the occurrence of a new magma input in the degassed and cooled 2014 reservoir. We can thus speculate that stress field change related to progressive deep magma transfer has promoted volatile exsolution, melt-crystal separation and melt expansion in the shallow reservoir. Textural heterogeneity of the 2014 products partly reflects a pre-eruptive physical gradient recorded by the variability in crystal and bubble contents in the shallow reservoir feeding this eruption. The golden and fluidal fragments are the bubble-richer and hotter portion of the melt. The spiny fragments are the degassed and cooler portion of the reservoir, whose progressive tapping led to a decrease in explosive intensity (from fountaining to Strombolian activity). Our results are also consistent with processes of mechanical reservoirs and/or dike stratification, as observed by Menand 
and Phillips (2007). As explained earlier, magma ascent promoted syn-eruptive degassing-induced crystallization. The spiny opaque clasts can be considered as recycled material that fell back into the system. Accumulation of olivine crystals out of equilibrium with the host magma produces minor variations in mesocryst contents as observed within the same type of clasts sampled at different times and locations during the eruption, with the scoriae from the WF and early erupted lava being the ones with the lowest amount of olivine (Table S4 and Fig. 7b). Again, this temporal variation supports an increase in large heavy crystals within the most degassed magma emitted toward the end of activity, further suggesting that it corresponds to the lower part of the reservoir.

Our dataset permits us to propose that the 2014 eruption was fed by a physically zoned magma reservoir. The lowdensity crystal-poor, bubble-rich magma located in the upper part of the storage system ascended first rapidly and fed the early, more energetic phase, the Hawaiian fountaining. This low-density magma is not more evolved than the spiny one (same bulk compositions) and it is not necessarily richer in dissolved volatile amounts; it is just poorer in crystal and richer in bubbles. Second boiling, possibly triggered a few days before the eruption by stress field change, is responsible for the extraction of bubble-rich melt from a crystal-rich network. This last one will represent the main volume of the erupted lava. Fast ascent of the foam hinders its crystallization and preserves a high number of vesicles, high vesicularity and it is only a little modified by post-fragmentation expansion. Decrease in initial over-pressure translates into a progressive decrease in magma ascent rate and output rate (e.g. Coppola et al., 2017, and references therein). Nucleation of microcrysts is enhanced in melt ascending with lower speed and is mostly related to syn-eruptive degassing (for the spiny fragments). The larger volume (dense lava) corresponds to crystallized and less vesiculated magma, which experiences a slow ascent in the dike and even further microcrystallization during its subaerial emplacement.

Melt inclusion results allow us to confirm the involvement of a single and only slightly heterogeneous magma source in 2014, related to cooling and fractional crystallization of an older magma batch (November 2009). Interestingly, this latter short-lived summit eruption was also characterized by the same large textural range of pyroclastic products found in 2014 in spite of its more mafic composition.

This suggests that bubble accumulation and source pressurization is highly dependent on the shallow storage depth, which facilitates rapid water exsolution (Di Muro et al., 2016), and it is not necessarily the outcome of slow magma cooling and differentiation (Tait et al., 1989).

\section{Proposed model for the 2014 eruption and conclusions}

In this paper we show that textural and petrochemical study of the eruptive products can be used to characterize the ongoing activity at $\mathrm{PdF}$ and to constrain both the trigger and the evolution of short-lived and small-volume eruptions. This approach is extremely valuable in (i) understanding processes that lead to an eruption that was preceded by short-lived and elusive precursors and (ii) in reconstructing the time evolution of eruptive dynamics in an eruption with poor direct observations.

Following the sketch in Fig. 12, we infer that residual magma from the 2009 eruption ponding at shallow levels experienced long-lasting cooling and crystallization (Fig. 12a). Between 2010 and 2014 the volcano progressively deflated (Fig. 12b), possibly because of magma degassing and cooling, facilitated by the shallow depth of the reservoir. During this phase mesocrysts and some microcrysts formed (Figs. 4e and 10a).

The occurrence of deep ( $>10 \mathrm{~km}$ b.s.l.) lateral magma transfer since March-April 2014 has been inferred by Boudoire et al. (2017) on the basis of deep (mantle level) seismic swarms and increase in soil $\mathrm{CO}_{2}$ emissions on the distal western volcano flank. The incipit of magma transfer towards shallower crustal levels is potentially recorded by subtle volcano inflation about 11 days before the June 2014 eruptions (Figs. 1d and 12c). We suspect that these deep processes can have progressively modified the shallow crustal stress field and favoured magma vesiculation and melt-crystal separation. Second boiling could thus have over-pressured the shallowly seated reservoir and triggered magma ascent (Fig. 12c).

Without this deep magma transfer we believe that the small reservoir activated in 2014 would have cooled down completely to form an intrusion (as suggested by the pervasive crystallization of the lava, one of the densest emitted from 2014 to 2017; Harris et al., 2017). The 2014 event represented instead the first of a long series of eruptions, whose magmas became progressively less evolved in time (Coppola et al., 2017). In this scenario the trigger mechanisms of 2014 activity are both internal and external in the sense that the small shallow reservoir hosting cooled magma permitted the creation of the conditions favourable to a second boiling (Fig. 12c, and Tait et al., 1989). The second boiling was likely triggered by an almost undetectable stress field change and was favoured by the shallow storage pressure of the magma (Fig. 12c) that promoted fast water exsolution and rapid magma response to external triggers. The second boiling possibly contributed to the inflation registered 11 days before the eruption at $1.4-1.7 \mathrm{~km}$ (Fig. 12c) caused by both magma expansion and transfer of hot fluids to the hydrothermal system (Lénat et al., 2011).

Our data permit the exclusion of (i) new magma input and/or fluid inputs $\left(\mathrm{CO}_{2}\right.$-rich fluids) from deep magmatic 

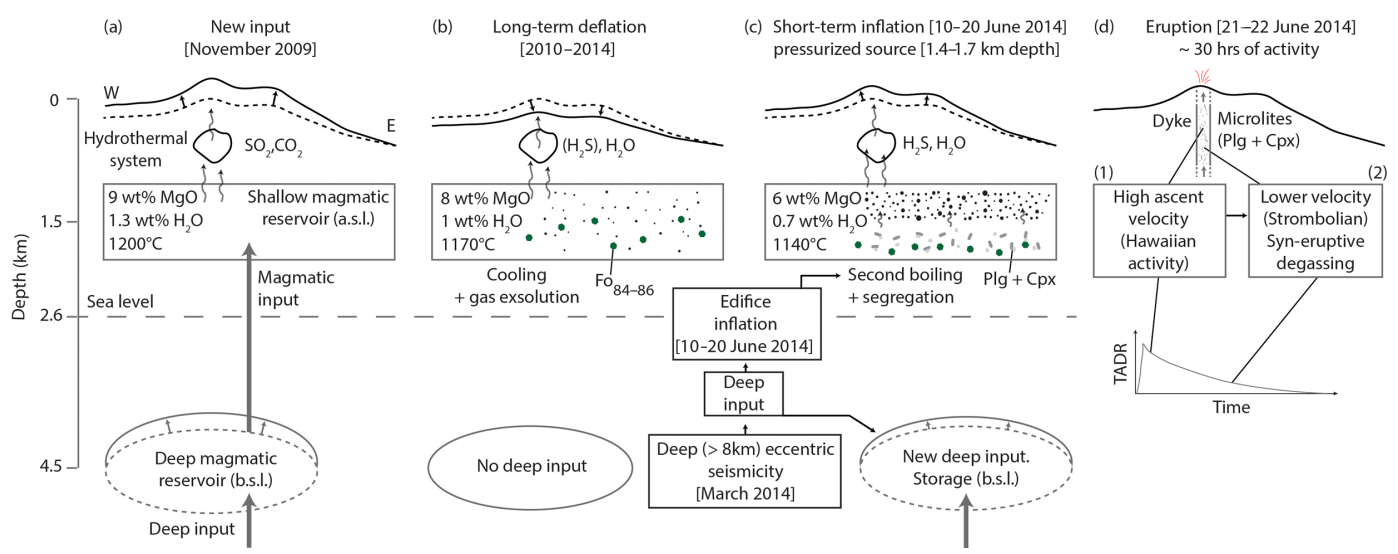

Figure 12. Schematic model of the evolution of the PdF volcanic system from the new deep magmatic input of November 2009 up to the June 2014 eruption. See explanation in the text.

levels to trigger the June 2014 eruption. We also exclude (ii) heating and enhanced convection of the shallow magma reservoir (due to heat diffusion without fluid or mass transfer) because this process is very slow. Furthermore, the 2014 minerals do not record evidence of magma heating. We can equally exclude (iii) deformation of the volcanic edifice and decompression of the magma reservoir and/or hydrothermal system due to flank sliding because geodetic data show no evidence of flank sliding able to produce stress change in the hydrothermal and magmatic system. Geophysical and geochemical data have permitted the tracking of vertical magma and fluid transfer below the volcano summit in April 2015, about 1 year after the early deep lateral magma transfer (Peltier et al., 2016). Deep processes are difficult to detect for any monitoring network.

We conclude that the over-pressure, caused by the second boiling, triggered the eruption. The occurrence of a hydrous, almost pure melt at shallow depth permitted its fast vesiculation upon ascent towards the surface. In turn, fast ascent of the foam (Fig. 12d) hindered its crystallization and preserved a high number of vesicles. Decrease in initial overpressure translated into a progressive decrease in magma ascent rate and output rate (e.g. Coppola et al., 2017, and references therein) and a temporal transition from Hawaiian activity to Strombolian activity (Fig. 12d). Nucleation of microcrysts was enhanced in melt ascending with lower speed and in turn this syn-eruptive crystallization favoured bubble connectivity and permeability in the ascending magma, even for magma at low vesicularity. The largest volume (dense lava) corresponds to highly crystallized and degassed magma already in the reservoir that experienced a slower ascent in the dike and even further micro-crystallization during its subaerial emplacement.

The texture of the products allowed us to follow the dynamic evolution of the system in space, from smooth fluidal scoriae emitted from a rapid jet of lava at the fractures, to a more stable activity at the MV, and in time. At the MV, in fact, we observed the transition from the golden and fluidal fragments emitted from Hawaiian fountaining, at the peak of the intensity of the eruption, to the spiny fragments, emitted from a declining Strombolian activity at the end of the eruption.

Therefore we here show for the first time that short-lived and weak Hawaiian fountaining and Strombolian events can preserve pyroclast textures that can be considered a valid approximation to shallow reservoir conditions and ascent degassing processes before the explosions and correlate to the eruptive dynamics as well.

To conclude, these results highlight the importance of petrological monitoring, which can provide complementary information regarding the ongoing volcanic activity to other geophysical and geochemical monitoring tools commonly used on volcanoes.

Data availability. The textural raw data and glass and bulk chemistry data are available at the DynVolc database (2017) https://doi. org/10.25519/DYNVOLC-Database, 2017. This is an open-access database. All the other data are reported in the Supplement.

\section{The Supplement related to this article is available online at https://doi.org/10.5194/se-9-431-2018-supplement.}

Competing interests. The authors declare that they have no conflict of interest.

Acknowledgements. We thank the OVPF team and T. Lecocq for monitoring and fieldwork. F. van Wyk de Vries provided an English revision for a previous version of the paper. We thank the STRAP project funded by the Agence Nationale de la Recherche (ANR-14-CE03-0004-04). This research was financed 
by the French Government Laboratory of Excellence initiative no. ANR-10-LABX-0006, the Région Auvergne and the European Regional Development Fund. This is Laboratory of Excellence Clervolc contribution number 288.

Edited by: Michael Heap

Reviewed by: Amanda Lindoo, Madison Myers, and one anonymous referee

\section{References}

Albarède, F. and Tamagnan, V.: Modelling the recent geochemical evolution of the Piton de la Fournaise volcano, Réunion island, 1931-1986, J. Petrol., 29, 997-1030, 1988.

Albarède, F., Luais, B., Fitton, G., Semet, M. P., Kaminski, E., Upton, B. G. J, Bachèlery, P., and Cheminée, J. L.: The geochemical regimes of Piton de la Fournaise Volcano Réunion. during the last 530,000 years, J. Petrol., 38, 171-201, 1997.

Andronico, D., Lo Castro, M. D., Sciotto, M., and Spina, L.: The 2010 ash emissions at the summit craters of Mt Etna: relationship with seismo-acoustic signals, J. Geophys. Res., 118, 51-70, https://doi.org/10.1029/2012JB009895, 2013a.

Andronico, D., Taddeucci, J., Cristaldi, A., Miraglia, L., Scarlato, P., and Gaeta, M.: The 15 March 2007 paroxysm of Stromboli: video-image analysis, and textural and compositional features of the erupted deposit, Bull. Volcanol., 75, 733, https://doi.org/10.1007/s00445-013-0733-2, 2013b.

Andronico, D., Scollo, S., Lo Castro, M. D., Cristaldi, A., Lodato, L., and Taddeucci, J.: Eruption dynamics and tephra dispersal from the 24 November 2006 paroxysm at South-East Crater, Mt Etna, Italy, J. Volcanol. Geotherm. Res., 274, 78-91, https://doi.org/10.1016/j.jvolgeores.2014.01.009, 2014.

Bachèlery, P., Lénat, J. F., Di Muro, A., and Michon, L.: Active Volcanoes of the Southwest Indian Ocean: Piton de la Fournaise and Karthala. Active Volcanoes of the World, Springer-Verlag, Berlin and Heidelberg, 1-428, https://doi.org/10.1007/978-3642-31395-0_12, 2016.

Boivin, P. and Bachèlery, P.: Petrology of 1977 to 1998 eruptions of Piton de la Fournaise, La Réunion Island, J. Volcanol. Geotherm. Res., 184, 109-125, 2009.

Bombrun, M., Harris, A., Gurioli, L., Battaglia, J., and Barra, V.: Anatomy of a strombolian eruption: inferences from particle data recorded with thermal video, J. Geophys. Res., 120, 2367-2387, https://doi.org/10.1002/2014JB011556, 2015.

Boudoire, G., Liuzzo, M., Di Muro, A., Ferrazzini, V., Michon, L., Grassa, F., Derrien, A., Villeneuve, N., Bourdeu, A., Brunet, C., Giudice, G., and Gurrieri, S.: Investigating the deepest part of a volcano plumbing system: evidence for an active magma path below the western flank of Piton de la Fournaise (La Réunion Island), J. Volcanol. Geotherm. Res., 341, 193-207, https://doi.org/10.1016/j.jvolgeores.2017.05.026, 2017.

Brenguier, F., Kowalski, P., Staudacher, T., Ferrazzini, V., Lauret, F., Boissier, P., Lemarchand, A., Pequegnat, C., Meric, O., Pardo, C., Peltier, A., Tait, S., Shapiro, N. M., Campillo, M., and Di Muro, A.: First Results from the UnderVolc High Resolution Seismic and GPS network deployed on Piton de la Fournaise Volcano, Seismo. Res. Lett., 83, 97-102, https://doi.org/10.1785/gssrl.83.1.97, 2012.
Brugier, Y. A.: Magmatologie du Piton de la Fournaise (Ile de la Réunion): approche volcanologique, pétrologique et expérimentale, Sciences de la Terre, Université d'Orléans, NNT: 2016ORLE2007, 251 pp., 2016.

Bureau, H., Pineau, F., Métrich, N., Semet, P. M., and Javoy, M.: A melt and fluid inclusion study of the gas phase at Piton de la Fournaise volcano (Reunion Island), Chem. Geol., 147, 115-130, 1998a.

Bureau, H., Métrich, N., Pineau, F., and Semet, M. P.: Magmaconduit interaction at Piton de la Fournaise volcano (Réunion Island): a melt and fluid inclusion study, J. Volcanol. Geotherm. Res., 84, 39-60, 1998 b.

Carey, R. J., Manga, M., Degruyter, W., Swanson, D., Houghton, B., Orr, T., and Patrick, M.: Externally triggered renewed bubble nucleation in basaltic magma: the 12 October 2008 eruption at Halema'uma'u Overlook vent, Kīlauea, Hawai'i, USA, J. Geophys. Res., 117, B11202, https://doi.org/10.1029/2012JB009496, 2012.

Carey, R. J., Manga, M., Degruyter, W., Gonnermann, H., Swanson, D., Houghton, B., Orr, T., and Patrick, M.: Convection in a volcanic conduit recorded by bubbles, Geology, 41, 395-398, 2013.

Cashman, K. V. and Mangan, M. T.: Physical aspects of magmatic degassing II: constraints on vesiculation processes from textural studies of eruptive products, in: Volatiles in magmas, edited by: Carroll, M. R. and Holloway, J. R., Reviews in mineralogy, Miner. Soc. Am., Fredricksberg, 447-478, 1994.

Clocchiatti, R., Havette, A., and Nativel, P.: Relations pétrogénétiques entre les basaltes transitionnels et les océanites du Piton de la Fournaise (Ile de La Réunion, océan Indien) à partir e la composition chimique des inclusions vitreuses des olivines et des spinelles, Bull. Minér., 102, 511-525, 1979.

Colombier, M., Gurioli, L., Druitt, T. H., Shea, T., Boivin, P., Miallier, D., and Cluzel, N.: Textural evolution of magma during the 9.4-ka trachytic explosive eruption at Kilian Volcano, Chaîne des Puys, France, Bull. Volcanol., 79, 1-24, https://doi.org/10.1007/s00445-017-1099-7, 2017a.

Colombier, M., Wadsworth, F. B., Gurioli, L., Scheu, B., Kueppers, U., Di Muro, A., and Dingwel, D. B.: The evolution of pore connectivity in volcanic rocks, Earth Planet. Sci. Lett., 462, 99-109, https://doi.org/10.1016/j.eps1.2017.01.011, 2017b.

Colò, L., Ripepe, M., Baker, D. R., and Polacci, M.: Magma vesiculation and infrasonic activity at Stromboli open conduit volcano, Earth Planet. Sci. Lett., 292, 274-280, 2010.

Coppola, D., Villeneuve, N., Di Muro, A., Ferrazzini, V., Peltier, A., Favalli, M., Bachèlery, P., Gurioli, L., Harris, A., Moune, S., Vlastélic, I., Galle, B., Arellano, S., and Aiuppa, A.: A Shallow system rejuvenation and magma discharge trends at Piton de la Fournaise volcano (La Réunion Island), Earth Planet. Sci. Lett., 463, 13-24, 2017.

Corsaro, R. and Miraglia, L.: The transition from summit to flank activity at Mt. Etna, Sicily (Italy): Inferences from the petrology of products erupted in 2007-2009, J. Volcanol. Geother. Res., 275, 51-60, 2014.

Di Muro, A., Métrich, N., Vergani, D., Rosi, M., Armienti, P., Fougeroux, T., Deloule, E., Arienzo, I., and Civetta, L.: The shallow plumbing system of Piton de la Fournaise Volcano (La Réunion Island, Indian Ocean) revealed by the major 2007 caldera forming eruption, J. Petrol., 55, 1287-1315, 2014. 
Di Muro, A., Staudacher, T., Ferrazzini, V., Métrich, N., Besson, P., Garofalo, C., and Villemant, B.: Shallow magma storage at Piton de la Fournaise volcano after 2007 summit caldera collapse tracked in Pele's hairs, chap 9 of Carey, R. J., edited by: Cayol, V., Poland, M. P., and Weis, D., Hawaiian Volcanoes: From Source to Surface, American Geophysical Union Monograph, 208, 189-212, https://doi.org/10.1002/9781118872079.ch9, 2015.

Di Muro, A., Métrich, N., Allard, P., Aiuppa, A., Burton, M., Galle, B., and Staudacher, T.: Magma degassing at Piton de la Fournaise volcano, Active Volcanoes of the World, series, Springer, edited by: Bachelery, P., Lenat, J. F., Di Muro, A., and Michon, L., 203222, 2016.

DYNVOLC Database: Observatoire de Physique du Globe de Clermont-Ferrand, Aubière, France, available at: https://doi.org/10.25519/DYNVOLC-Database, 2017.

Eychenne, J., Houghton, B. F., Swanson, D. A., Carey, R. J., and Swavely, L.: Dynamics of an open basaltic magma system: the 2008 activity of the Halema'uma'u Overlook vent, Kilauea Caldera, Earth Planet. Sci. Lett., 409, 49-60, 2015.

Famin, V., Welsch, B., Okumura, S., Bachèlery, P., and Nakashima, S.: Three differentiation stages of a single magma at Piton de la Fournaise (Réunion hotspot), Geochem. Geophys. Geosyst., 10, Q01007, https://doi.org/10.1029/2008GC002015, 2009.

Fisk, M. R., Upton, B. G. J., Ford, C. E., and White, W. M.: Geochemical and experimental study of the genesis of magmas of Reunion island, Indian Ocean, J. Geophys. Res., 93, 4933-4950, 1988.

Formenti, Y. and Druitt, T. H.:, Vesicle connectivity in pyroclasts and implications for the fluidisation of fountain-collapse pyroclastic flows, Montserrat (West Indies), Earth Planet. Sci. Lett., 214, 561-574, 2003.

Gardner, J. E., Thomas, R. M. E., Jaupart, C., and Tait, S.: Fragmentation of magma during Plinian volcanic eruptions, Bull. Volcanol., 58, 144-162, 1996.

Giachetti, T., Druitt, T. H., Burgisser, A., Arbaret, L., and Galven, C.: Bubble nucleation and growth during the 1997 Vulcanian explosions of Soufrière Hills Volcano, Montserrat, J. Volcanol. Geotherm. Res., 193, 215-231, https://doi.org/10.1016/j.jvolgeores.2010.04.001, 2010.

Gonnermann, H. M. and Manga, M.: Dynamics of magma ascent in the volcanic conduit, in: Modeling Volcanic Processes: The Physics and Mathematics of Volcanism, edited by: Fagents, S. A., Gregg, T. K. P., and Lopes, R. M. C., Cambridge University Press, Cambridge, 2013.

Gurioli, L., Harris, A. J. L., Houghton, B. F., Polacci, M., and Ripepe, M.: Textural and geophysical characterization of explosive basaltic activity at Villarrica volcano, J. Geophys. Res., 113, B08206, https://doi.org/10.1029/2007JB005328, 2008.

Gurioli, L., Harris, A. J. L., Colo, L., Bernard, J., Favalli, M., Ripepe, M., and Andronico, D.: Classification, landing distribution and associated flight parameters for a bomb field emplaced during a single major explosion at Stromboli, Italy, Geology, 41, 559-562, https://doi.org/10.1130/G33967.1, 2013.

Gurioli, L., Colo', L., Bollasina, A. J., Harris, A. J. L., Whittington, A., and Ripepe, M.: Dynamics of strombolian explosions: inferences from inferences from field and laboratory studies of erupted bombs from Stromboli volcano, J. Geophys. Res., 119, 319-345, https://doi.org/10.1002/2013JB010355, 2014.
Gurioli, L., Andronico, D., Bachelery, P., Balcone-Boissard, H., Battaglia, J., Boudon, G., Burgisser, A.,Burton, S. B. M. R., Cashman, K., Cichy, S., Cioni, R., Di Muro, A., Dominguez, L., D’Oriano, C., Druitt, T., Harris, A. J. L., Hort, M., Kelfoun, K., Komorowski, J. C., Kueppers, U., Le Pennec, J. L., Menand, T., Paris, R., Pioli, L., Pistolesi, M., Polacci, M., Pompilio, M., Ripepe, M., Roche, O., Rose-Koga, E., Rust, A., Scharff, L., Schiavi, F., Sulpizio, R., Taddeucci, J., and Thordarson, T.: MeMoVolc consensual document: a review of cross-disciplinary approaches to characterizing small explosive magmatic eruptions, Bull. Volcanol., 77, 49, https://doi.org/10.1007/s00445015-0935-x, 2015.

Hammer, J. E., Cashman, K. V., Hoblitt, R. P., and Newman, S.: Degassing and microlite crystallization during pre-climactic events of the 1991 eruption of Mt. Pinatubo, Philippines, Bull. Volcanol., 60, 355-380, 1999.

Harris, A. J. L., Villeneuve, N., Di Muro, A., Ferrazzini, V., Peltier, A., Coppola, D., Favalli, M., Bachèlery, P., Foger, J.-L., Gurioli, L., Moune, S., Vlastélic, I., Galle, B., and Arellano, S.: Effusive Crises at Piton de la Fournaise 2014-2015: A Review of a Multi-National Response Model, Appl. Volcanol., 6, 1-29, https://doi.org/10.1186/s13617-017-0062-9, 2017.

Helz, R. T. and Thornber, C. R.: Geothermometry of Kilauea Iki lava lake, Hawaii, Bull. Volcanol., 49, 651-668, 1987.

Hibert, C., Mangeney, A., Polacci, M., Di Muro, A., Vergniolle, S., Ferrazzini, V., Taisne, B., Burton, M., Dewez, T., Grandjean, G., Dupont, A., Staudacher, T., Brenguier, F., Shapiro, N. M., Kowalski, P., Boissier, P., Catherine, P., and Lauret, F.: Multidisciplinary monitoring of the January 2010 eruption of Piton de la Fournaise volcano, La Réunion island, J. Geophys. Res., 120, 3026-3047, 2015.

Higgins, M.-D.: Measurement of crystal size distributions, Am. Mineral., 85, 1105-1116, 2000.

Houghton, B. F. and Wilson, C. J. N.: A vesicularity index for pyroclastic deposits, Bull. Volcanol., 51, 451-462, https://doi.org/10.1007/BF01078811, 1989.

Houghton, B. F., Swanson, D. A., Carey, R. J., Rausch, J., and Sutton, A. J.: Pigeonholing pyroclasts, insights from the 19 March 2008 explosive eruption of Killauea volcano, Geology, 39, 263266, https://doi.org/10.1130/G31509.1, 2011.

Houghton, B. F., Swanson, D. A., Rausch, J., Carey, R. J., Fagents, S. A., and Orr, T. R.: Pushing the volcanic explosivity index to its limit and beyond: constraints from exceptionally weak explosive eruptions at K1lauea in 2008, Geology, 41, 627-630, 2013.

Houghton, B. F., Taddeucci, J., Andronico, D., Gonnermann, H. M., Pistolesi, M., Patrick, M. R., Orr, T. R., Swanson, D. A., Edmonds, M., Gaudin, D., Carey, R. J., and Scarlato, P.: Stronger or longer: Discriminating between Hawaiian and Strombolian eruption styles, Geology, 44, 163-166, https://doi.org/10.1130/G37423.1, 2016.

Inman, D. L.: Measures for describing the size distribution of sediments, J. Sed. Petrol., 22, 125-145, 1952.

Jordan, S. C., Le Pennec, J.-L., Gurioli, L., Roche, O., and Boivin, P.: Highly explosive eruption of the monogenetic $8.6 \mathrm{ka} \mathrm{BP}$ La Vache et Lassolas scoria cone complex (Chaîne des Puys, France), J. Volcanol. Geotherm. Res., 313, 15-28, 2016.

Kahl, M., Chakraborty, S., Pompilio, M., and Costa, F.: Constraints on the nature and evolution of the magma plumbing system of Mt. Etna Volcano (1991-2008) from a com- 
bined thermodynamic and kinetic modelling of the compositional record of minerals, J. Petrol., 56, 2025-2068, https://doi.org/10.1093/petrology/egv063, 2015.

Kawabata, E., Cronin, S. J., Bebbington, M. S., Moufti, M. R. H., El-Masry, N., and Wang, T.: Identifying multiple eruption phases from a compound tephra blanket: an example of the AD1256 Al-Madinah eruption, Saudi Arabia, Bull. Volcanol., 77, 6, https://doi.org/10.1007/s00445-014-0890-y, 2015.

Lange, R. A., Frey, H. M., and Hector, J.: A thermodynamic model for the plagioclase-liquid hygrometer/thermometer, Am. Mineral., 94, 494-506, 2009.

Lautze, N., Taddeucci, J., Andronico, D., Cannata, C., Tornetta, L., Scarlato, P., Houghton, B., and Lo Castro, D.: SEM-based methods for the analysis of basaltic ash from weak explosive activity at Etna in 2006 and the 2007 eruptive crisis at Stromboli, Phys. Chem. Earth, 45, 113-127, https://doi.org/10.1016/j.pce.2011.02.001, 2012.

Leduc, L., Gurioli, L., Harris, A. J. L., Colo', L., and Rose-Koga, E.: Types and mechanisms of strombolian explosions: characterization of a gas-dominated explosion at Stromboli, Bull. Volcanol., 77, 8, https://doi.org/10.1007/s00445-014-0888-5, 2015.

Lénat, J.-F., Bachèlery, P., and Peltier, A.: The interplay between collapse structures, hydrothermal systems and magma intrusions: the case of the central area of Piton de la Fournaise volcano, Bull. Volc., 74, 407-421, https://doi.org/10.1007/s00445-011-0535-3, 2011.

Lénat, E. F., Bachelery, P. B., and Merle, O.: Anatomy of Piton de la Fournaise volcano (La Réunion, Indian Ocean), Bull. Volcanol., 74, 1945-1961, 2012.

Lengliné, O., Duputel, Z., and Ferrazzini, V.: Uncovering the hidden signature of a magmatic recharge at Piton de la Fournaise volcano using small earthquakes, Geophys. Res. Lett., 43, 42554262, https://doi.org/10.1002/2016GL068383, 2016.

Lindoo, A., Larsen, J. F., Cashman, K. V., Dunn, A. L., and Neill, O. K.: An experimental study of permeability development as a function of crystal-free melt viscosity, Earth Planet. Sci. Lett., 435, 45-54, https://doi.org/10.1016/j.epsl.2015.11.035, 2016.

Lindoo, A., Larsen, J. F., Cashman, K. V., and Oppenheimer, J.: Crystal controls on permeability development and degassing in basaltic andesite magma, Geology, 45, 831-834, 2017.

Liuzzo, M., Di Muro, A., Giudice, G., Michon, L., Ferrazzini, V., and Gurrieri, S.: New evidence of $\mathrm{CO}_{2}$ degassing anomalies on the Piton de la Fournaise volcano and the link with volcano tectonic structures, Geochem. Geophys. Geosyst., 16, 4388-4404, https://doi.org/10.1002/2015GC006032, 2015.

Mangan, M. T. and Cashman, K. V.: The structure of basaltic scoria and reticulite and inferences for vesiculation, foam formation, and fragmentation in lava fountains, J. Volcanol. Geotherm. Res., 73, 1-18, 1996.

Menand, T. and Phillips, J. C.: Gas segregation in dykes and sills, J. Volcanol. Geother. Res., 159, 393-408, https://doi.org/10.1016/j.jvolgeores.2006.08.003, 2007.

Michon, L., Di Muro, A., Villeneuve, N., Saint-Marc, C., Fadda, P., and Manta, F.: Explosive activity of the summit cone of Piton de la Fournaise volcano (La Réunion Island): a historical and geological review, J. Volcanol. Geotherm. Res., 263, 117-133, 2013.

Moitra, P., Gonnermann, H. M., Houghton, B. F., and Giachetti, T.: Relating vesicle shapes in pyroclasts to eruption styles, Bull.
Volcanol., 75, 691, https://doi.org/10.1007/s00445-013-0691-8, 2013.

Morgan D. J. and Jerram, D. A.: On estimating crystal shape for crystal size distribution analysis, J. Volc. Geotherm. Res., 154, 1-7, 2006.

Moune, S., Sigmarsson, O., Schiano, P., Thordarson, T., and Keiding, J. K.: Melt inclusion constraints on the magma source of Eyjafjallajökull 2010 flank eruption, J. Geophys. Res., 117, B00C07, https://doi.org/10.1029/2011jb008718, 2012.

Morandi, A., Principe, C., Di Muro, A., Leroi, G., Michon, L., and Bachèlery, P.: Pre-historic explosive activity at Piton de la Fournaise volcano, edited by: Bachèlery, P., Lénat, J. F., Di Muro, A., and Michon, L., in: Active Volcanoes of the Southwest Indian Ocean: Piton de la Fournaise and Karthala. Active Volcanoes of the World, Springer-Verlag, Berlin and Heidelberg, 107-138, 2016

Óladóttir, B., Sigmarsson, O., Larsen, G., and Devidal, J.-L.: Provenance of basaltic tephra from Vatnajökull subglacial volcanoes, Iceland, as determined by majorand trace-element analyses, Holocene, 21, 1037-1048, https://doi.org/10.1177/0959683611400456, 2011.

Oppenheimer, J., Rust, A. C., Cashman, K. V., and Sandnes, B.: Gas migration regimes and outgassing in particle-rich suspensions, Front. Phys., 3, 1-13, https://doi.org/10.3389/fphy.2015.00060, 2015.

Ort, M. H., Di Muro, A., Michon, L., and Bachèlery, P.: Explosive eruptions from the interaction of magmatic and hydrothermal systems during flank extension: the Bellecombe Tephra of Piton de La Fournaise (La Réunion Island), Bull. Volcanol., 78, 5, https://doi.org/10.1007/s00445-015-0998-8, 2016.

Papale, P., Moretti, R., and Barbato, D.: The compositional dependence of the saturation surface of $\mathrm{H}_{2} \mathrm{O}+$ $\mathrm{CO}_{2}$ fluids in silicate melts, Chem. Geol., 229, 78-95, https://doi.org/10.1016/j.chemgeo.2006.01.013, 2006.

Parcheta, C. E., Houghton, B. F., and Swanson, D. A.: Contrasting patterns of vesiculation in low, intermediate, and high Hawaiian fountains: a case study of the 1969 Mauna Ulu eruption, J. Volcanol. Geotherm. Res., 255, 79-89, 2013.

Peltier, A., Bachèlery, P., and Staudacher, T.: Magma transport and storage at Piton de la Fournaise (La Réunion) between 1972 and 2007: A review of geophysical and geochemical data, J. Volcanol. Geotherm. Res., 184, 93-108, 2009.

Peltier, A., Beauducel, F., Villeneuve, N., Ferrazzini, V., Di Muro, A., Aiuppa, A., Derrien, A., Jourde, K., and Taisne, B.: Deep fluid transfer evidenced by surface deformation during the 2014-2015 unrest at Piton de la Fournaise volcano, J. Volcanol. Geotherm. Res., 321, 140-148, https://doi.org/10.1016/j.jvolgeores.2016.04.031, 2016.

Polacci, M., Corsaro, R., and Andronico, D.: Coupled textural and compositional characterization of basaltic scoria: insights into the transition from Strombolian to fire fountain activity at Mount Etna, Italy, Geology, 34, 201-204, https://doi.org/10.1130/G22318.1, 2006.

Polacci, M., Bouvet de Maisonneuve, C., Giordano, D., Piochi, M., Mancini, L., Degruyter, W., and Bachmanng, O.: Permeability measurements of Campi Flegrei pyroclastic products: an example from the Campanian Ignimbrite and Monte Nuovo eruptions, J. Volcanol. Geotherm. Res., 272, 16-22, 2014. 
Putirka, K. D.: Thermometers and barometers for volcanic systems, Rev. Mineral. Geochem., 69, 61-120, 2008.

Roeder, P., Gofton, E., and Thornber, C.: Cotectic proportions of olivine and spinel in olivine-tholeiitic basalt and evaluation of pre-eruptive processes, J. Petrol., 47, 883-900, 2006.

Roult, G., Peltier, A., Staudacher, T., Ferrazzini, V., Taisne, B., Di Muro, A., and The OVPF Team: A comprehensive classification of the Piton de la Fournaise eruptions (La Réunion Island) spanning the 1986-2010 period. Search for eruption precursors from the broad-band GEOSCOPE RER station analysis and interpretation in terms of volcanic processes, J. Volcanol. Geotherm. Res., 241, 78-104, 2012.

Rust, A. C. and Cashman, K. V.: Permeability controls on expansion and size distributions of pyroclasts, J. Geophys. Res., 116, B11202, https://doi.org/10.1029/2011JB008494, 2011.

Saar, M. O., Manga, M., Cashman, K. V., and Fremouw, S.: Numerical models of the onset of yield strength in crystalmelt suspensions, Earth Planet. Sci. Lett., 187, 367-379, https://doi.org/10.1016/S0012-821X(01)00289-8, 2001.

Salaün, A., Villemant, B., Semet, M. P., and Staudacher, T.: Cannibalism of olivine-rich cumulate xenoliths during the 1998 eruption of Piton de la Fournaise (La Réunion hotspot): Implications for the generation of magma diversity, J. Volcanol. Geother. Res., 198, 187-204, 2010.

Schiano, P., David, K., Vlastélic, I., Gannoun, A., Klein, M., Nauret, F., and Bonnand, P.: Osmium isotope systematics of historical lavas from Piton de la Fournaise (Réunion Island, Indian Ocean), Contrib. Mineral. Petrol., 162, 995-1009, https://doi.org/10.1007/s00410-012-0774-0, 2012.

Shea, T.: Bubble nucleation in magmas: a dominantly heterogeneous process?, J. Volcanol. Geotherm. Res., 343, 155-170, 2017.

Shea, T., Houghton, B. F., Gurioli, L., Cashman, K. V., Hammer, J. E., and Hobden, B.: Textural studies of vesicles in volcanic rocks: an integrated methodology, J. Volcanol. Geotherm. Res., 190, 271-289, 2010.

Shea, T., Gurioli, L., and Houghton, B. F.: Transitions between fall phases and pyroclastic density currents during the AD 79 eruption at Vesuvius: building a transient conduit model from the textural and volatile record, Bull. Volcanol., 74, 2363-2381, https://doi.org/10.1007/s00445-012-0668-z, 2012.

Sparks, R. S. J.: The dynamics of bubble formation and growth in magmas: a review and analysis, J. Volcanol. Geotherm. Res., 3, 1-37, 1978.

Sparks, R. S. J.: Forecasting volcanic eruptions, Earth Planet. Sci. Lett., 210, 1-15, 2003.

Spina, L., Cimarelli, C., Scheu, B., Di Genova, D., and Dingwell, D. B.: On the slow decompressive response of volatile- and crystalbearing magmas: An analogue experimental investigation, Earth Planet. Sci. Lett., 433, 44-53, 2016.

Staudacher, T. and Peltier, A.: Ground deformation at Piton de la Fournaise (La Réunion Island), a review from 20 years of GNSS monitoring, edited by: Bachèlery, P., Lénat, J. F., Di Muro, A., and Michon, L., in: Active volcanoes of the Southwest Indian Ocean: Piton de la Fournaise and Karthala. Active volcanoes of the world, Springer, Berlin, 139-170, https://doi.org/10.1007/978-3-642-31395-0_9, 2015.

Staudacher, T., Ferrazzini, V., Peltier, A., Kowalski, P., Boissier, P., Catherine, P., Lauret, F., and Massin, F.: The April
2007 eruption and the Dolomieu crater collapse, two major events at Piton de la Fournaise (La Réunion Island, Indian Ocean), J. Volcanol. Geother. Res., 184, 126-137, https://doi.org/10.1016/j.jvolgeores.2008.11.005, 2009.

Stovall, W. K., Houghton, B. F., Gonnermann, H. M., Fagents, S. A., and Swanson, D. A.: Eruption dynamics of Hawaiian-style fountains: the case study of episode 1 of the Kîlauea Iki 1959 eruption, Bull. Volcanol., 73, 511-529. https://doi.org/10.1007/s00445-010-0426-z, 2011.

Stovall, W. K., Houghton, B. F., Hammer, J. E., Fagents, S. A., and Swanson, D. A.: Vesiculation of high fountaining Hawaiian eruptions: episodes 15 and 16 of 1959 Kîlauea Iki, Bull. Volcanol., 74, 441-455, https://doi.org/10.1007/s00445-011-0531-7, 2012.

Swanson, D. A., Wooten, K., and Orr, T.: Buckets of ash track tephra flux from Halema'uma'u crater, Hawai'i, Eos Trans. AGU, 90, 427-428, https://doi.org/10.1029/2009EO460003, 2009.

Taddeucci, J., Pompilio, M., and Scarlato, P.: Monitoring the explosive activity of the July-August 2001 eruption of Mt. Etna (Italy) by ash characterization, Geophys. Res. Lett., 29, 10291032, https://doi.org/10.1029/2001GL014372, 2002.

Tait, S., Jaupart, C., and Vergniolle, S.: Pressure, gas content and eruption periodicity of a shallow, crystallising magma chamber, Earth Planet. Sci. Lett., 92, 107-123, 1989.

Takeuchi, S., Nakashima, S., and Akihiko Tomiya, A.: Permeability measurements of natural and experimental volcanic materials with a simple permeameter: toward an understanding of magmatic degassing processes, J. Volcanol. Geotherm. Res., 177, 329-339, 2008.

Thordarson, T., Self, S., Óskarsson, N., and Hulsebosch, T.: Sulfur, chlorine and fluorine degassing and atmospheric loading by the 1783-1784 AD Laki (Skaftár Fires) eruption in Iceland, Bull. Volcanol., 58, 205-225, 1996.

Thornber, C. R., Hon, K., Heliker, C., and Sherrod, D. A.: A Compilation of Whole-Rock and Glass Major-Element geochemistry of Kîlauea Volcano, Hawai'i, near-vent eruptive products: January 1983 through September 2001: U.S.G.S. Open File Report, 03-477, 2003.

Villemant, B., Salaün, A., and Staudacher, T.: Evidence for a homogeneous primary magma at Piton de la Fournaise (La Réunion): A geochemical study of matrix glass, melt inclusions and Pélé's hairs of the 1998-2008 eruptive activity, J. Volcanol. Geotherm. Res., 184, 79-92, 2009.

Vlastélic, I. and Pietruszka, A. J.: A review of the recent geochemical evolution of Piton de la Fournaise Volcano (1927-2010), edited by: Bachèlery, P., Lénat, J. F., Di Muro, A., and Michon, L., Active Volcanoes of the Southwest Indian Ocean, in: Active Volcanoes of the World, 185-201, 2016.

Vlastélic, I., Peltier, A., and Staudacher, T.: Short-term (1998-2006) fluctuations of $\mathrm{Pb}$ isotopes at Piton de la Fournaise volcano (Réunion Island): origins and constraints on the size and shape of the magma reservoir, Chem. Geol., 244, 202-220, 2007.

Vlastélic, I., Deniel, C., Bosq, C., Telouk, P., Boivin, P., Bachèlery, P., Famin, V., and Staudacher, T.: Pb isotope geochemistry of Piton de la Fournaise historical lavas, J. Volcanol. Geother. Res., 184, 63-78, 2009.

Vlastélic, I., Staudacher, T., Bachèlery, P., Télouk, P., Neuville, D., and Benbakkar, M.: Lithium isotope fractionation during magma degassing: constraints from silicic differentiates and natural gas 
condensates from Piton de la Fournaise volcano (Réunion Island), Chem. Geol., 284, 26-34, 2011.

Vlastélic, I., Menard, G., Gannoun, M., Piro, J.-L., Staudacher, T., and Famin, V.: Magma degassing during the April 2007 collapse of Piton de la Fournaise: the record of semi-volatile trace elements (Li, B, Cu, In, Sn, Cd, Re, Tl, Bi), J. Volcanol. Geother. Res., 254, 94-107, 2013.

Vlastélic, I., Staudacher, T., and Semet, M.: Rapid change of lava composition from 1998 to 2002 at Piton de la Fournaise (Réunion) inferred from $\mathrm{Pb}$ isotopes and trace elements: evidence for variable crustal contamination, J. Petrol., 46, 79-107, 2005.
Welsch, B., Faure, F., Bachèlery, P., and Famin, V.: Microcrysts record transient convection at Piton de la Fournaise volcano (La Réunion Hotspot), J. Petrol., 50, 2287-2305, 2009.

Welsch, B., Famin, V., Baronnet, A., and Bachèlery, P.: Dendritic crystallization: a single process for all textures of olivine in basalts?, J. Petrol., 54, 539-574, 2013.

White, J. D. L. and Houghton, B. F.: Primary volcaniclastic rocks, Geology, 34, 677-680, https://doi.org/10.1130/G22346.1, 2006. 